\title{
The global impact of non-communicable diseases on macro-economic productivity: a systematic review
}

\author{
Layal Chaker ${ }^{1,2} \cdot$ Abby Falla ${ }^{3,4} \cdot$ Sven J. van der Lee ${ }^{1}$ Taulant Muka ${ }^{1}$ • \\ David Imo ${ }^{1} \cdot$ Loes Jaspers $^{1} \cdot$ Veronica Colpani $^{1} \cdot$ Shanthi Mendis $^{5}$.

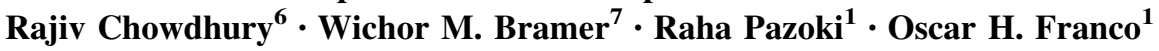

Received: 7 October 2014/ Accepted: 24 March 2015/Published online: 3 April 2015

(c) The Author(s) 2015. This article is published with open access at Springerlink.com

\begin{abstract}
Non-communicable diseases (NCDs) have large economic impact at multiple levels. To systematically review the literature investigating the economic impact of NCDs [including coronary heart disease (CHD), stroke, type 2 diabetes mellitus (DM), cancer (lung, colon, cervical and breast), chronic obstructive pulmonary disease (COPD) and chronic kidney disease (CKD)] on macro-economic productivity. Systematic search, up to November 6th 2014, of medical databases (Medline, Embase and Google Scholar) without language
\end{abstract}

Layal Chaker, Abby Falla and Sven J. van der Lee have contributed equally to this work.

Electronic supplementary material The online version of this article (doi:10.1007/s10654-015-0026-5) contains supplementary material, which is available to authorized users.

Oscar H. Franco

o.franco@erasmusmc.nl

1 Department of Epidemiology, Erasmus MC, University Medical Center Rotterdam, Office NA29-16, PO Box 2040, 3000 CA Rotterdam, The Netherlands

2 Department of Endocrinology, Erasmus MC, Rotterdam, The Netherlands

3 Department of Public Health, Erasmus MC, Rotterdam, The Netherlands

4 Division of Infectious Disease Control, Municipal Public Health Service (GGD) Rotterdam-Rijnmond, Rotterdam, The Netherlands

5 Chronic Diseases Prevention and Management, Department of Chronic Diseases and Health Promotion, World Health Organization, Geneva, Switzerland

6 Department of Public Health and Primary Care, University of Cambridge, Cambridge, UK

7 Medical Library, Erasmus MC, Rotterdam, The Netherlands restrictions. To identify additional publications, we searched the reference lists of retrieved studies and contacted authors in the field. Randomized controlled trials, cohort, case-control, cross-sectional, ecological studies and modelling studies carried out in adults ( $>18$ years old) were included. Two independent reviewers performed all abstract and full text selection. Disagreements were resolved through consensus or consulting a third reviewer. Two independent reviewers extracted data using a predesigned data collection form. Main outcome measure was the impact of the selected NCDs on productivity, measured in DALYs, productivity costs, and labor market participation, including unemployment, return to work and sick leave. From 4542 references, 126 studies met the inclusion criteria, many of which focused on the impact of more than one NCD on productivity. Breast cancer was the most common $(n=45)$, followed by stroke $(n=31)$, COPD $(n=24)$, colon cancer $(n=24), D M(n=22)$, lung cancer $(\mathrm{n}=16), \operatorname{CVD}(\mathrm{n}=15)$, cervical cancer $(\mathrm{n}=7)$ and CKD $(\mathrm{n}=2)$. Four studies were from the WHO African Region, 52 from the European Region, 53 from the Region of the Americas and 16 from the Western Pacific Region, one from the Eastern Mediterranean Region and none from South East Asia. We found large regional differences in DALYs attributable to NCDs but especially for cervical and lung cancer. Productivity losses in the USA ranged from 88 million US dollars (USD) for COPD to 20.9 billion USD for colon cancer. CHD costs the Australian economy 13.2 billion USD per year. People with DM, COPD and survivors of breast and especially lung cancer are at a higher risk of reduced labor market participation. Overall NCDs generate a large impact on macro-economic productivity in most WHO regions irrespective of continent and income. The absolute global impact in terms of dollars and DALYs remains an 
elusive challenge due to the wide heterogeneity in the included studies as well as limited information from lowand middle-income countries.

Keywords Noncommunicable diseases - Productivity . Return to work absenteeism - Systematic review

\section{Introduction}

Non-communicable diseases (NCDs), such as coronary heart disease (CHD), stroke, chronic obstructive pulmonary disease (COPD), cancer, type 2 diabetes and chronic kidney disease (CKD) currently constitute the number one cause of morbidity and mortality worldwide, claiming 36 million lives each year (accounting for $63 \%$ of all adult deaths) [1]. Infectious disease prevention and control, economic growth, improvements in medical and scientific knowledge, and health and social systems development have all contributed to increased life expectancy, improved quality of life and increased likelihood of living to age 60 years and beyond. While these are notable achievements, together with lifestylerelated shifts, these epidemiological and socio-demographic changes also mean that the burden of NCDs will grow [2].

Productivity is a measure of the efficiency of a person, business or country in converting inputs into useful outputs. The productive age span of a person is from adulthood to retirement and ranges from 18 years to around 65 years of age depending on, amongst other things, profession and country. The measurement of productivity greatly relies on the output and the economic or social system context. The focus in this report is macro-economic productivity loss in the productive age range due to NCDs. Key macro-economic measures related to the labor market include: (un-) employment, (loss in) hours worked (including full or part-time work status change), presenteeism (defined as impaired performance while at work), absenteeism, disability adjusted life years (DALYs) and productivity costs/losses. Key macro-economic outcomes are reduction in the able workforce, NCD-related health and welfare expenditure and loss of income earned by the productive workforce. While both the burden of NCDs and the socio-economic contexts vary greatly, the impact of the former on macro-economic outcomes across the global regions remains unclear.

We aimed to systematically identify and summarize the literature investigating the impact of six NCDs (CHD, stroke, COPD cancer, type 2 diabetes and CKD) on macroeconomic productivity and to determine directions for future research.

\section{Methods}

\section{Search strategy and inclusion criteria}

We systematically searched the electronic medical databases (Medline, Embase and Google Scholar) up to November 6th, 2014 (date of last search) to identify relevant articles evaluating the macro-economic consequences of the six selected NCDs, specifically the impact on economic productivity of working age citizens. The complete search strategy is available in "Appendix 1". We defined the major NCDs of interest as CHD, stroke, chronic obstructive lung disease (COPD), type 2 diabetes mellitus (DM), cancer (lung, colon, breast and cervical) and chronic kidney disease (CKD). The step-wise inclusion and exclusion procedure is outlined in Fig. 1. Eligible study design included randomized controlled trials (RCTs), cohort, case-control, cross-sectional, systematic reviews, metaanalysis, ecological studies and modeling studies. We included studies that estimated the impact of at least one of the NCDs defined above on at least one of the following measures of macro-economic productivity: DALYs, economic costs related to reduced work productivity, absenteeism, presenteeism, (un) employment, (non-) return to work (RTW) after sickness absence and medical/sick leave. DALY is also considered as essentially it is an economic measure of human productive capacity for the affected individual and when taken together (e.g. all those in a company, society etc.) forms an economic measure also on the group level. Only studies involving adults ( $>18$ years old) were included, without any restriction on language or date.

\section{Study selection}

Two independent reviewers screened the titles and abstracts of the initially identified studies to determine if they satisfied the selection criteria. Any disagreements were resolved through discussion and consensus, or by consultation with a third reviewer. In order to ensure that all retrieved full texts (of the selected abstracts) satisfied the inclusion criteria appropriately, they were further assessed by two independent reviewers. We further screened the reference lists of all retrieved studies to retrieve relevant articles. Systematic reviews were not included in the data extraction but a supplementary scan of their reference lists was performed to identify any additional studies.

\section{Data extraction}

A data collection form (DCF) was prepared to extract the relevant information from the included full texts, including 


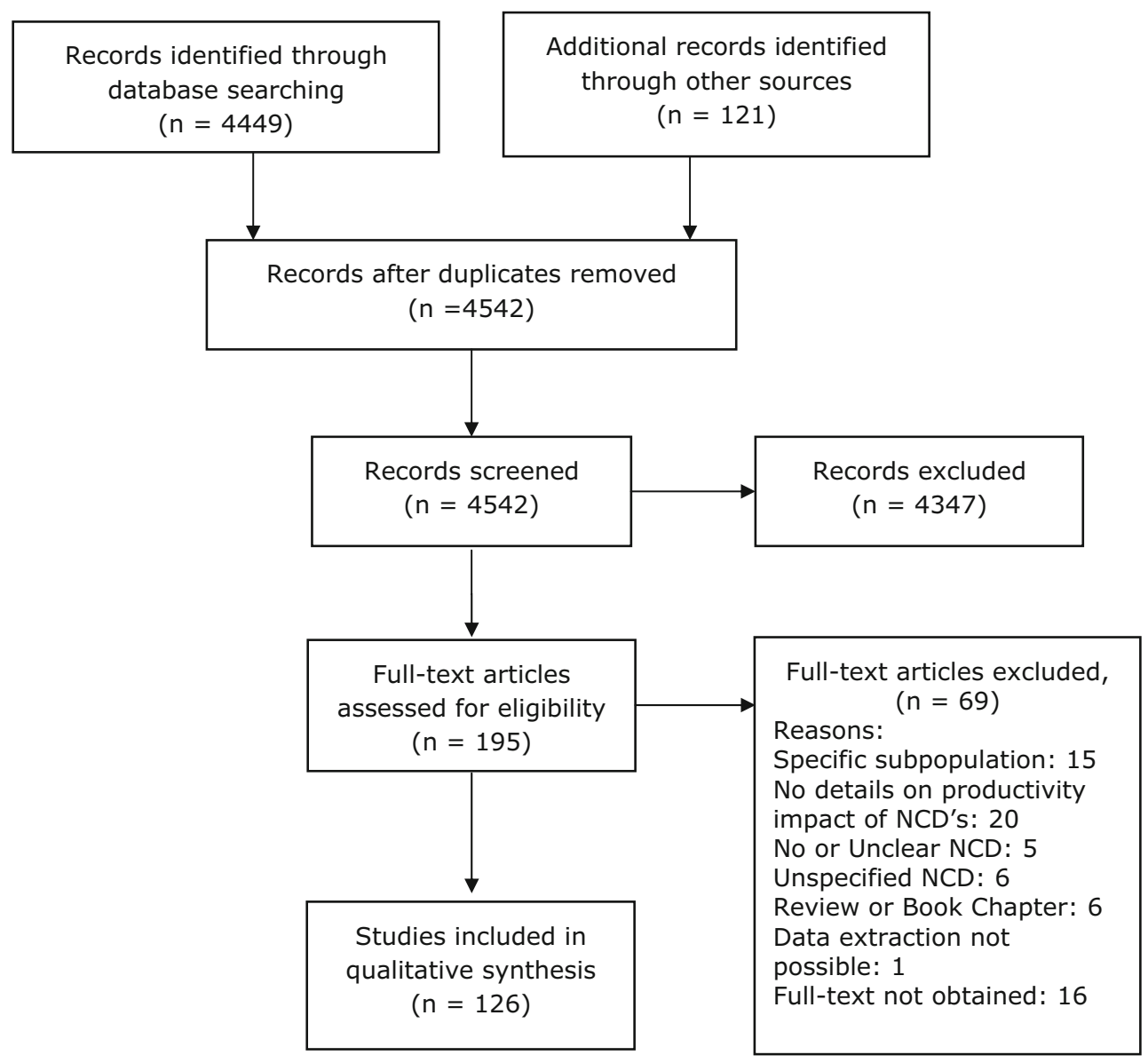

Fig. 1 Flowchart of studies for the global impact of non-communicable diseases on macro-economic productivity

study design, World Health Organization (WHO) region, participants, NCD-related exposure and macro-economic outcome characteristics. When evaluating economic costs, US dollars (USD) was used as outcome measure. If a study reported costs in another currency, the corresponding exchange rate to USD as reported by the study itself was used. However, if an exchange rate was not provided, we calculated USD applying the conversion rate for the indicated study time-period.

\section{Quality evaluation}

To evaluate the quality of the included non-randomized studies, we applied the Newcastle-Ottawa Scale (NOS) [3]. The NOS scale assesses the quality of articles in three domains: selection, comparability and exposure. 'Selection' assesses four items and a maximum of one star can be awarded for each item. 'Comparability' awards a maximum of two stars to the one item within the category. Finally, 'exposure' includes four items for which one star can be awarded. A quality score is made for each study by summing the number of stars awarded, and thus the NOS scale can have maximum of nine stars. We used this scale to assess the quality of case-control and cohort studies. For cross-sectional and descriptive studies, we used an adapted version of NOS scale ("Appendix 2").

\section{Statistical methods}

We aimed to pool the results using a random effects model. If pooled, results would be expressed as pooled relative risks with $95 \%$ confidence intervals. Pooling possibility was conditional on the level of heterogeneity between studies.

\section{Results}

\section{General characteristics of the included studies}

From 4542 references initially identified, a total of 126 unique studies met the inclusion criteria (Fig. 1; Table 1). All eligible studies were published between 1984 and 2014. Of the 126 studies identified, 52 were from the 


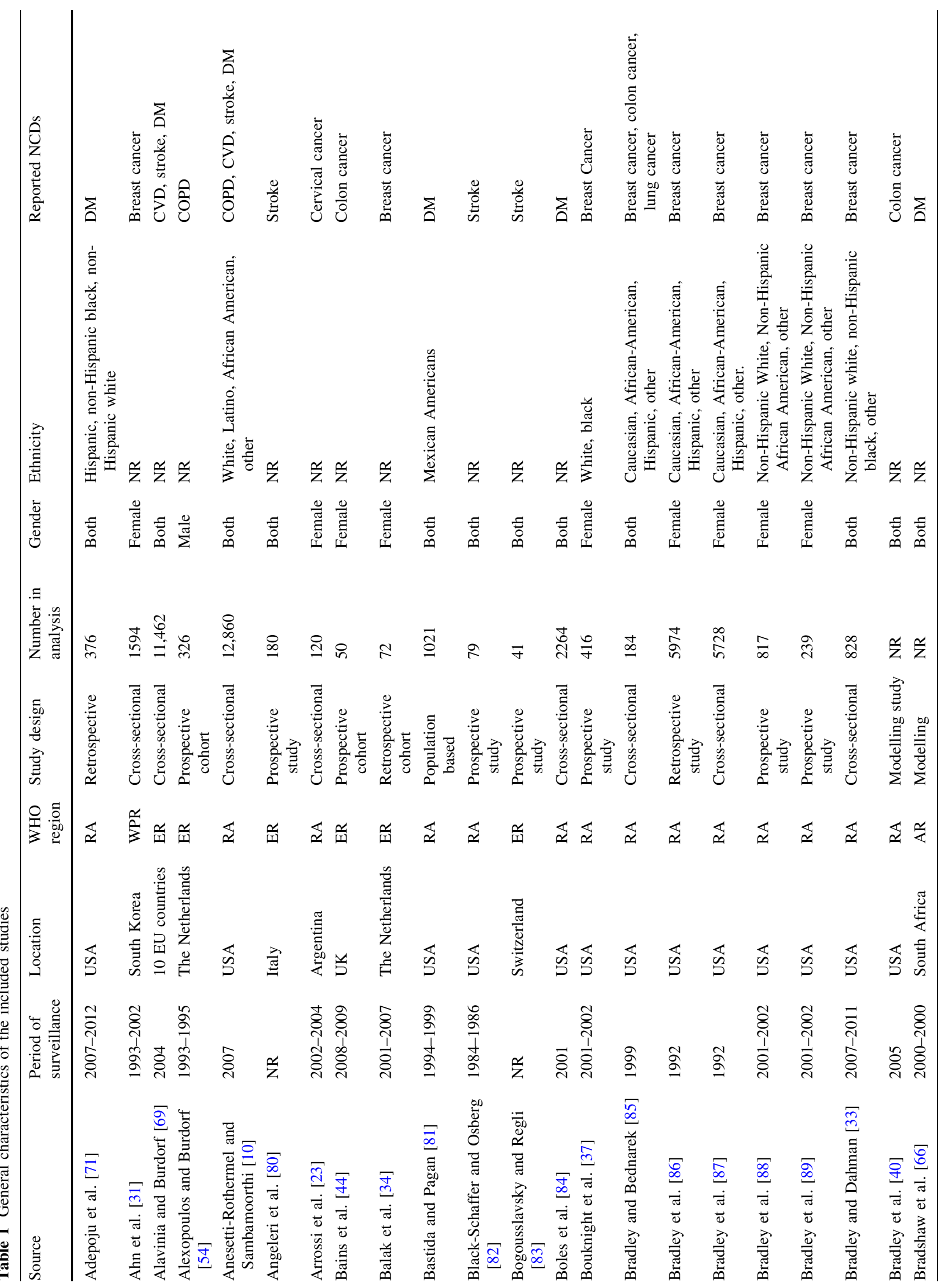




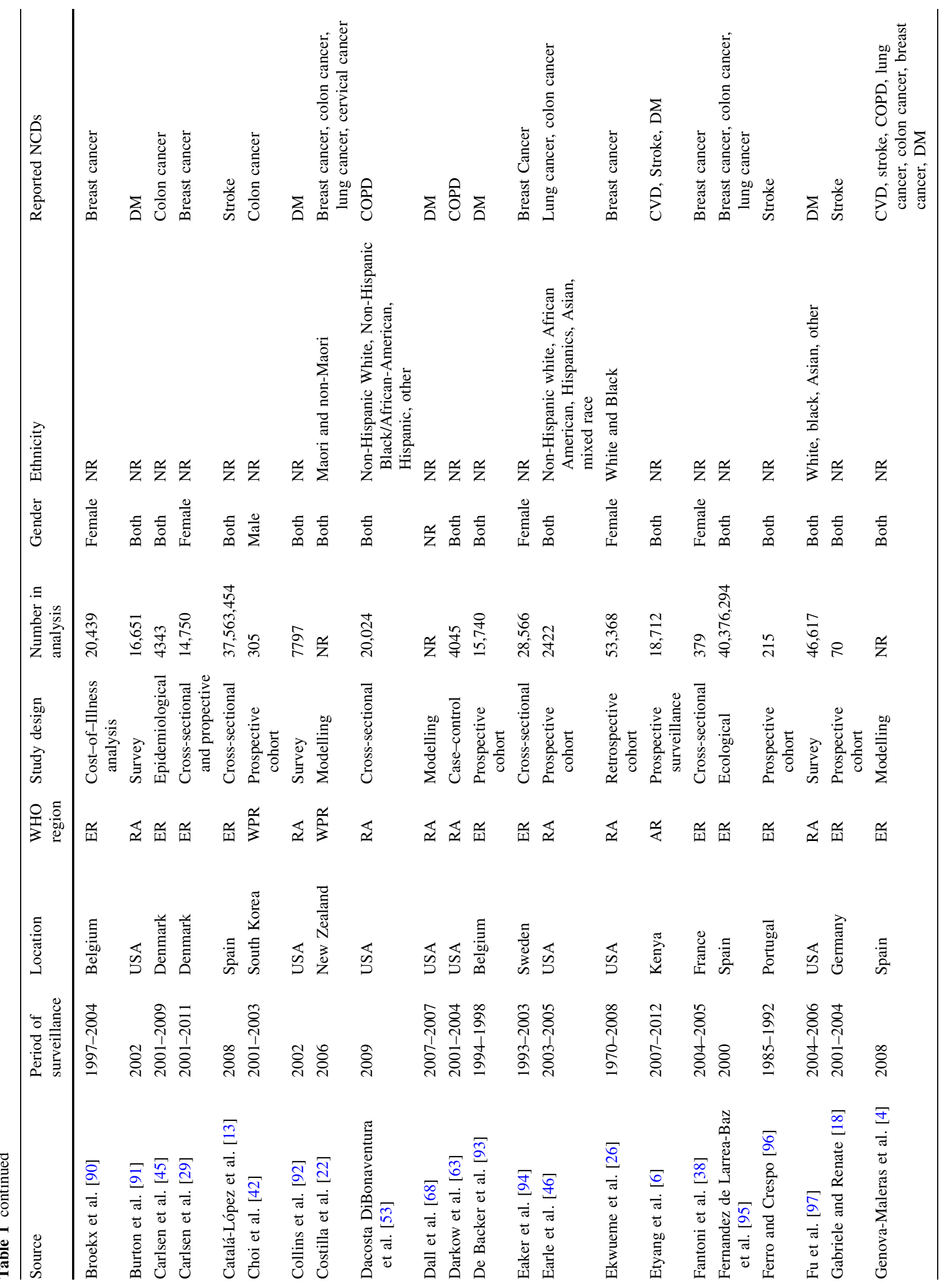




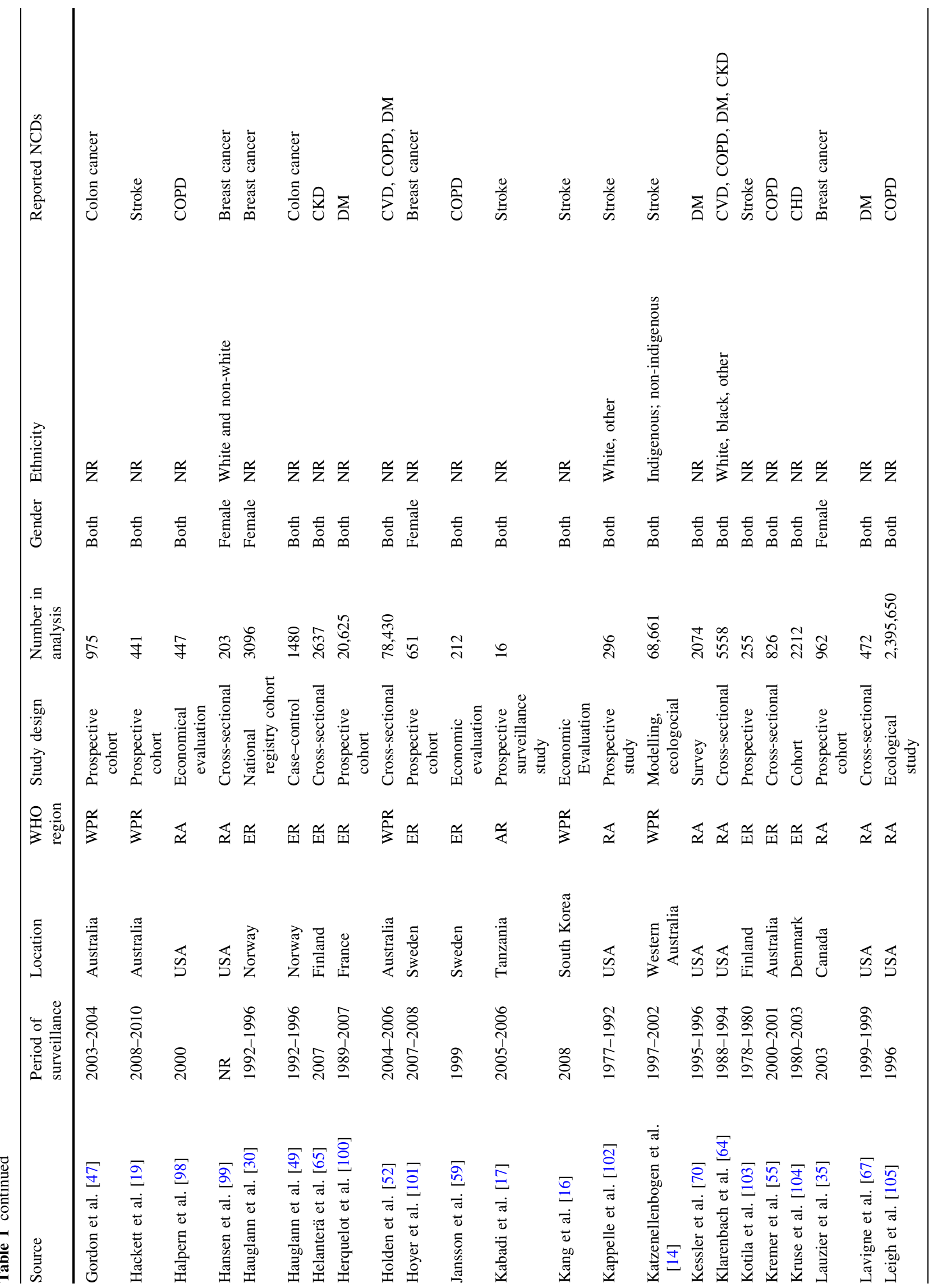




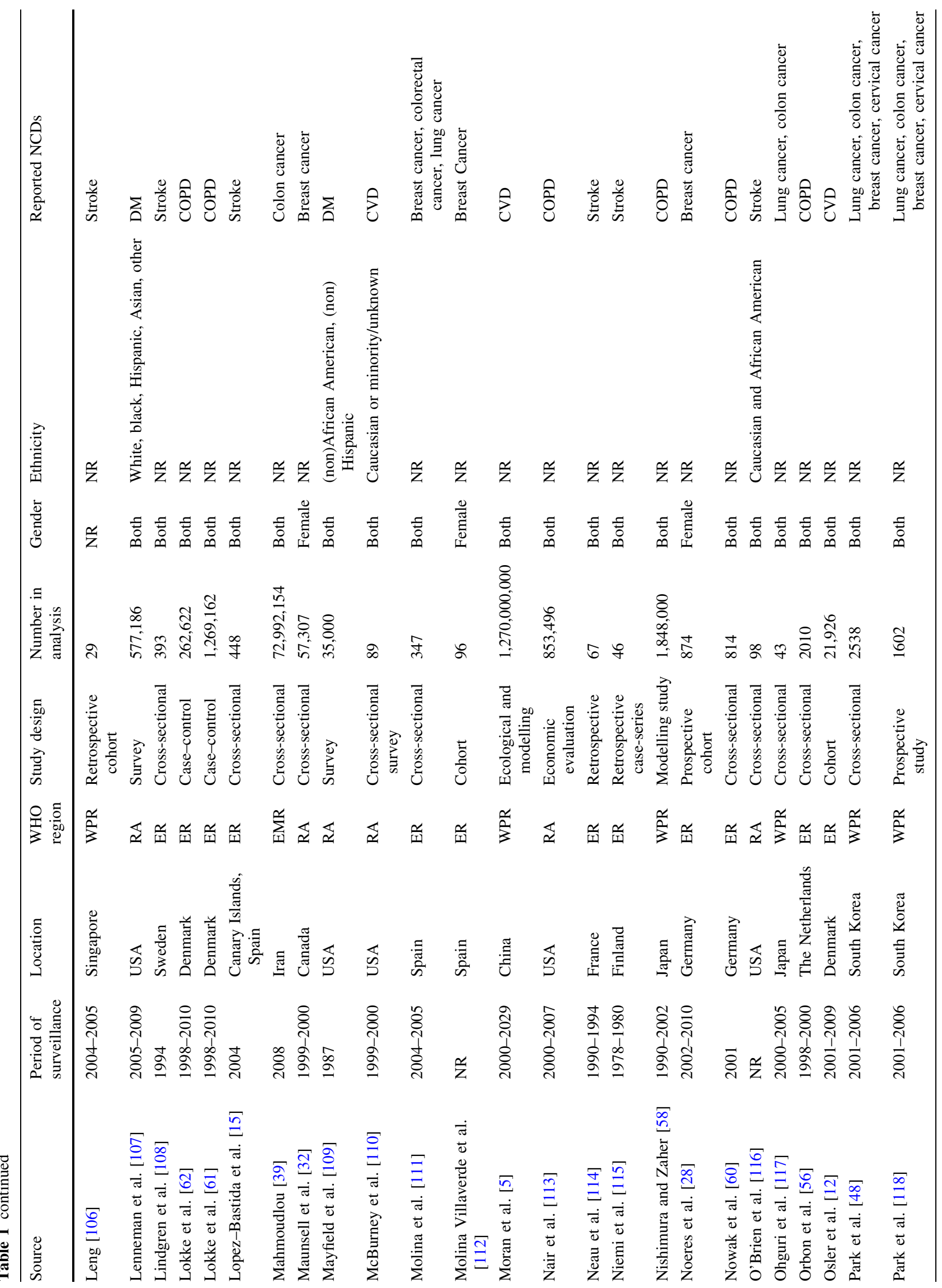




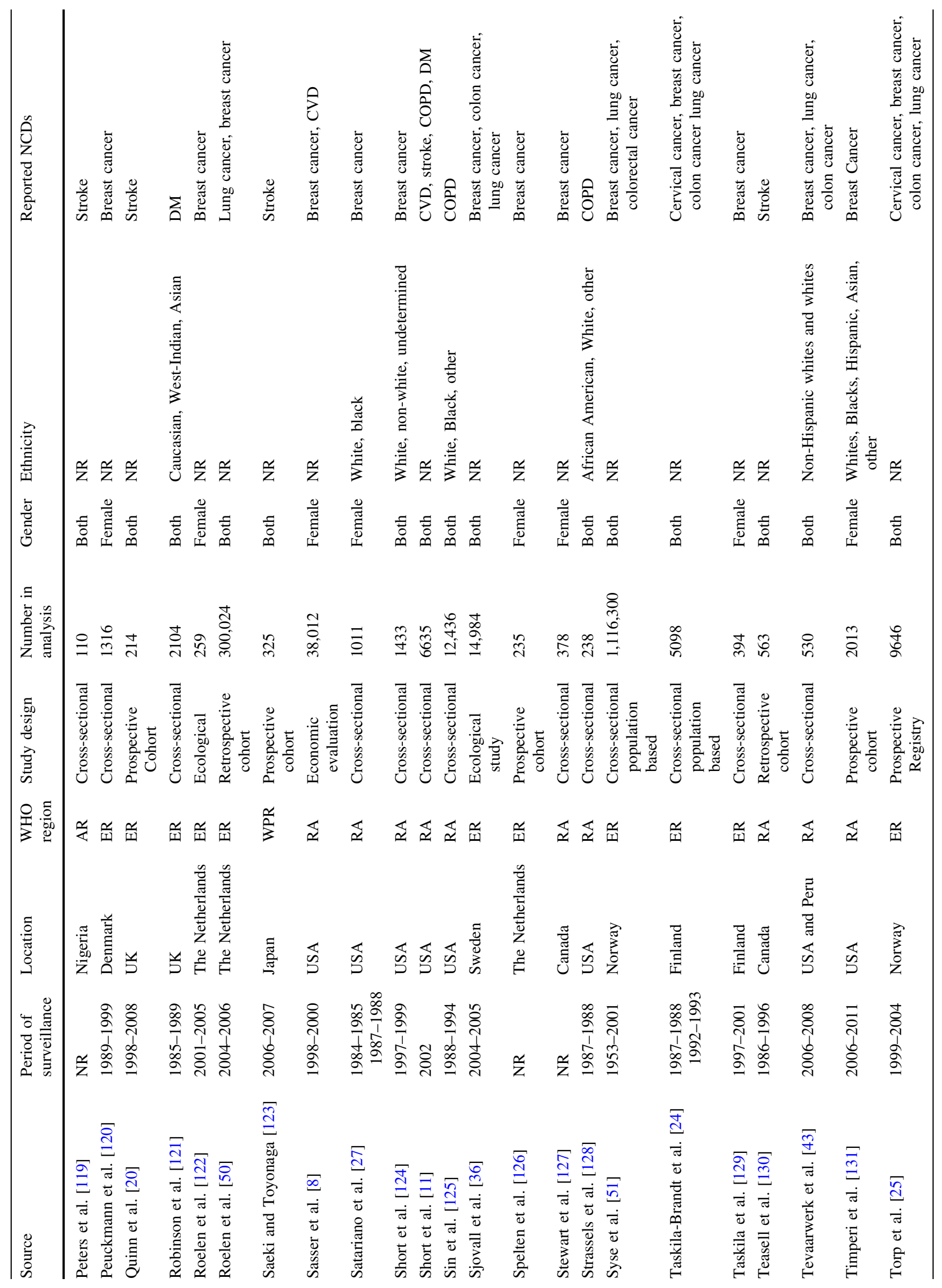




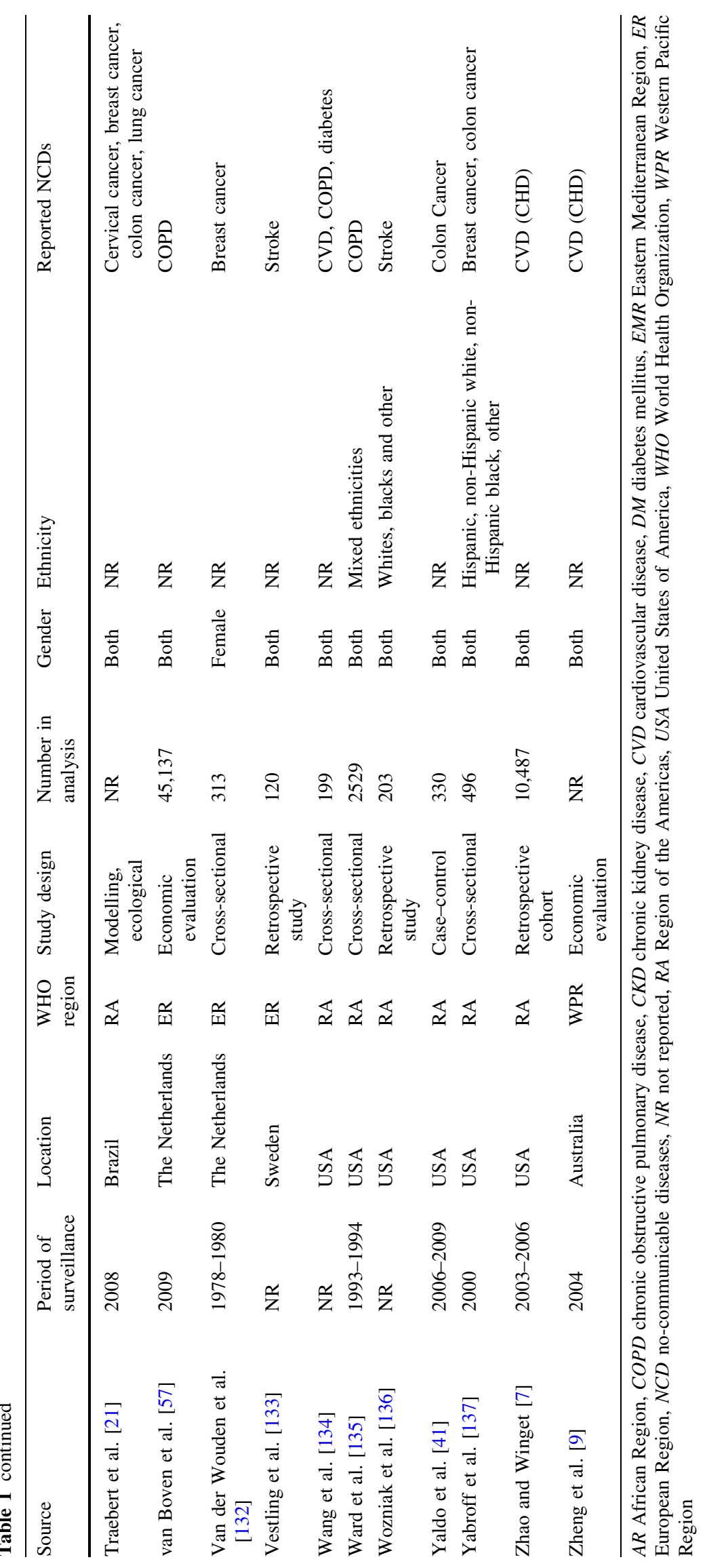


WHO European Region, 53 from the Region of the Americas (of which all but two were from Canada or the United States of America [USA]), 16 from the Western Pacific Region, four were from the WHO African Region and one from the Eastern Mediterranean Region. We found no studies from South East Asia. The majority of the identified studies were observational in design, analyzed prospectively as well as cross-sectional. Two studies reported cross-sectional data from an RCT and six were modeling studies. National or hospital-based disease registries were often used to select patients, which were in some cases linked to national socio-economic databases to extract corresponding employment data. The control group, if used, was often a sample from the general population and sometimes sought within the same environment of the patients (e.g. same company). Many studies focused on the impact of more than one NCD on productivity. Most studies used one measure of productivity. Of all the published studies including cancers, cervical cancer was included in seven studies, breast cancer in 45, colon cancer in 24 and lung cancer in 16. Stroke was included in a total of 31 studies, COPD in 24, DM in 22 and CHD was included in 15 studies. Relevant data on CKD was included in only two of the studies and two of the studies mention NCDs in general.

\section{Measures of productivity}

Measures of productivity impact in the available studies included DALYs, absenteeism, presenteeism, labor market (non-) participation, RTW, change in hours worked and medical/sickness leave. Most studies focused on the direct impact on the patient but a minority also examined the impact on caregivers/spouses. Outcomes were quantified using risks, proportions, odds, dollars, years and days. In some studies, time-to-event data was analyzed using Cox proportional-hazards regression. Adjusting for education, age and employment status was most frequently applied, although the measurement of education and employment was not consistently defined, measured or validated. A small minority of studies reported differences in impact according to ethnicity. Pooling of outcomes was not possible due to substantial heterogeneity across and within NCD groups $\left(I^{2}>70 \%\right)$.

\section{Impact of cardiovascular disease on productivity}

Of all DALYs on a population level in Spain (Table 2a), $4.2 \%$ were attributable to CHD [4] with an estimated agestandardized rate of 4.7 per 1000 persons per year. In China, DALYs attributable to CHD were estimated to be $8,042,000$ for the year 2000 and predicted to more than double in 2030 , rising up to $16,356,000$ [5]. In the same study, the estimated DALY in 2000 was 16.1 per 1000 persons and predicted to be 20.4 in 2030 (estimate not accounted for age). A study from Kenya estimated the DALY to be 68 per 100,000 person-years of observation [6]. CHD-related productivity loss in the USA was estimated to be 8539 USD per person per year (PP/PY), at 10175 USD PP/PY [7] for absenteeism and 2698 USD PP/ PY for indirect work-related loss [8]. Total absenteeismrelated costs in Australia were estimated at 5.69 billion USD, mortality-related costs at 23 million USD and costs related to lower employment at 7.5 billion USD [9]. An estimated 4.7 working days PP/PY were lost in the USA owing to CHD [10]. Also in the USA, the odds of experiencing limited amount of paid work due to illness were significantly higher for those with CHD compared to the control group, with an odds ratio (OR) of 2.91 for women (95\% CI 2.34-3.61) and 2.34 for men (95 \% CI 1.84-2.98) [11]. In Denmark workforce participation increased with increasing time from $37 \%$ after 30 days to $65 \%$ after 5 years of diagnosis [12]. In a study conducted in 10 European Union (EU) countries, no difference was found for the risk of non-participation in the labor force between those with and without self-reported CHD with an OR of 0.96 (95\% CI 0.66-1.40).

\section{Impact of stroke on productivity}

Stroke accounted for $3.5 \%$ of all DALYs reported in Spain (Table 2b) with a rate of 3.8 per 1000 people [4]. Another study from Spain reports a total count of DALYs of 418,052 with a higher number of male than for female $(220,005$ vs. 198,046) [13]. A study from Kenya reports a rate of 166 DALYs per 100,000 person-years observed [6]. In Western Australia, the average annual stroke-attributable DALY count is an estimated 26,315 for men and 30,918 for women [14]. In Spain, costs after diagnosis increased over time for caregivers but declined for patients $(14,732$ USD in caregivers compared to 2696 USD among patients after 1 year and 15,621 USD to 1362 USD after 2 years) [15]. Modeled productivity losses in South Korea were higher for a severe stroke among men (537,724 USD) than women (171,157 USD) [16]. A prospective surveillance study from Tanzania report a mean costs of productivity loss to be 213 USD [17]. Inconclusive evidence of the impact of stroke on RTW was reported. Estimates ranged from 26.7 to $75 \%$ in studies reporting RTW in stroke patients after 1 year of the event $[18,19]$. In Nigeria, $55 \%$ returned to work at a mean of 19.5 months after stroke. A report from the United Kingdom (UK) found that $47 \%$ were unemployed 1 year after stroke [20]. Increased odds to report limited ability for paid work were found among men (3.86) and women (2.26) after stroke [11]. 


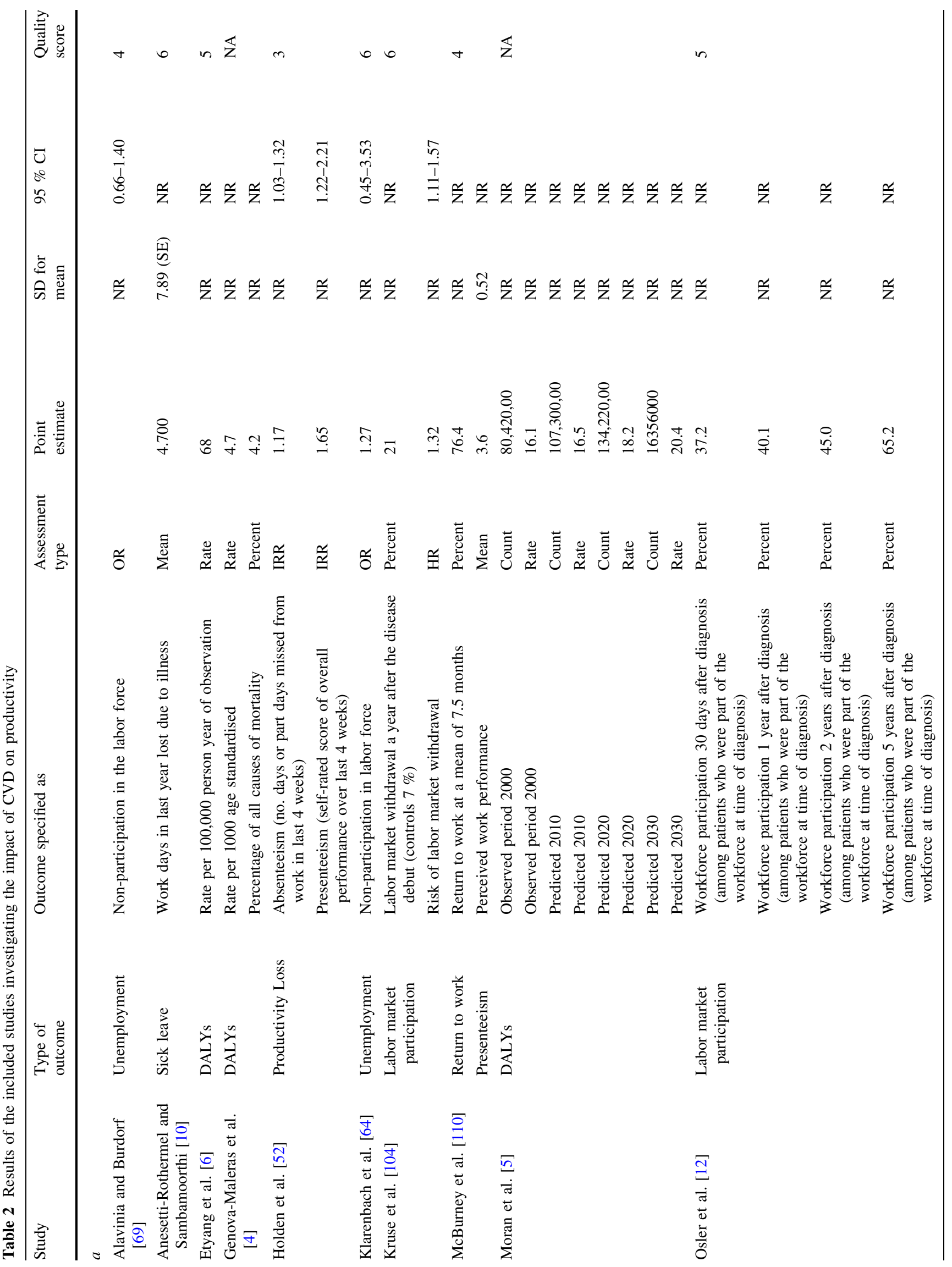




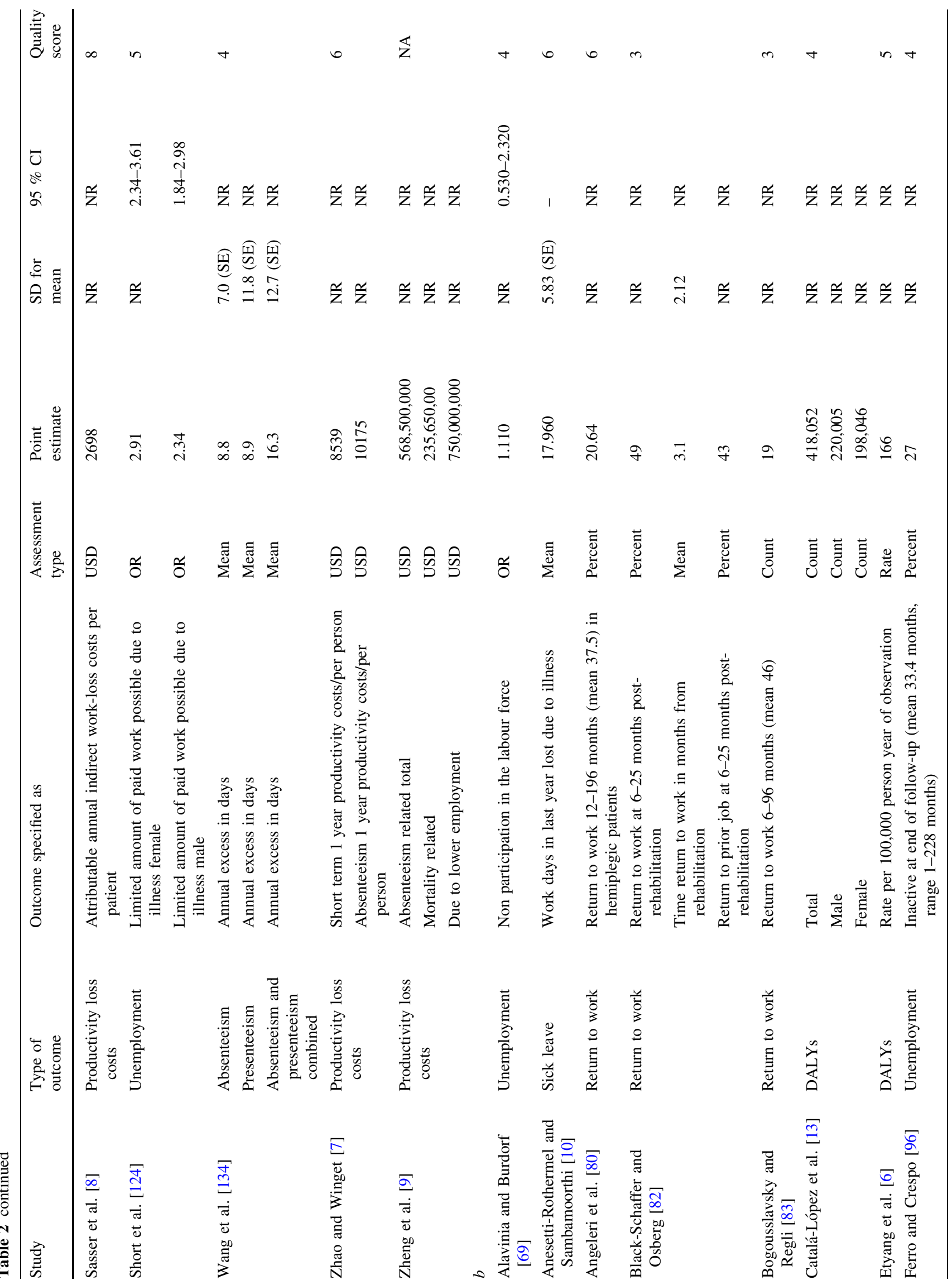




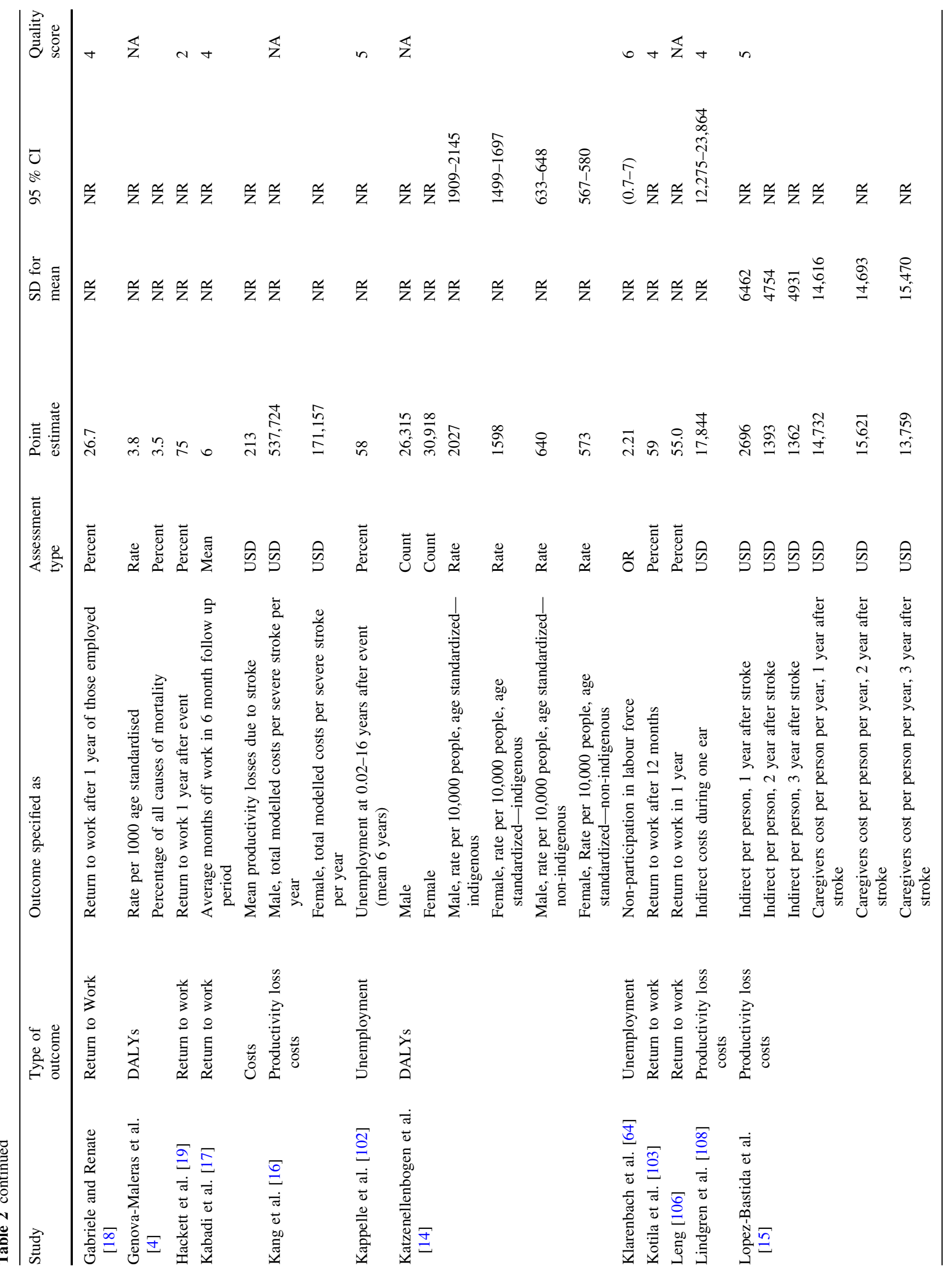




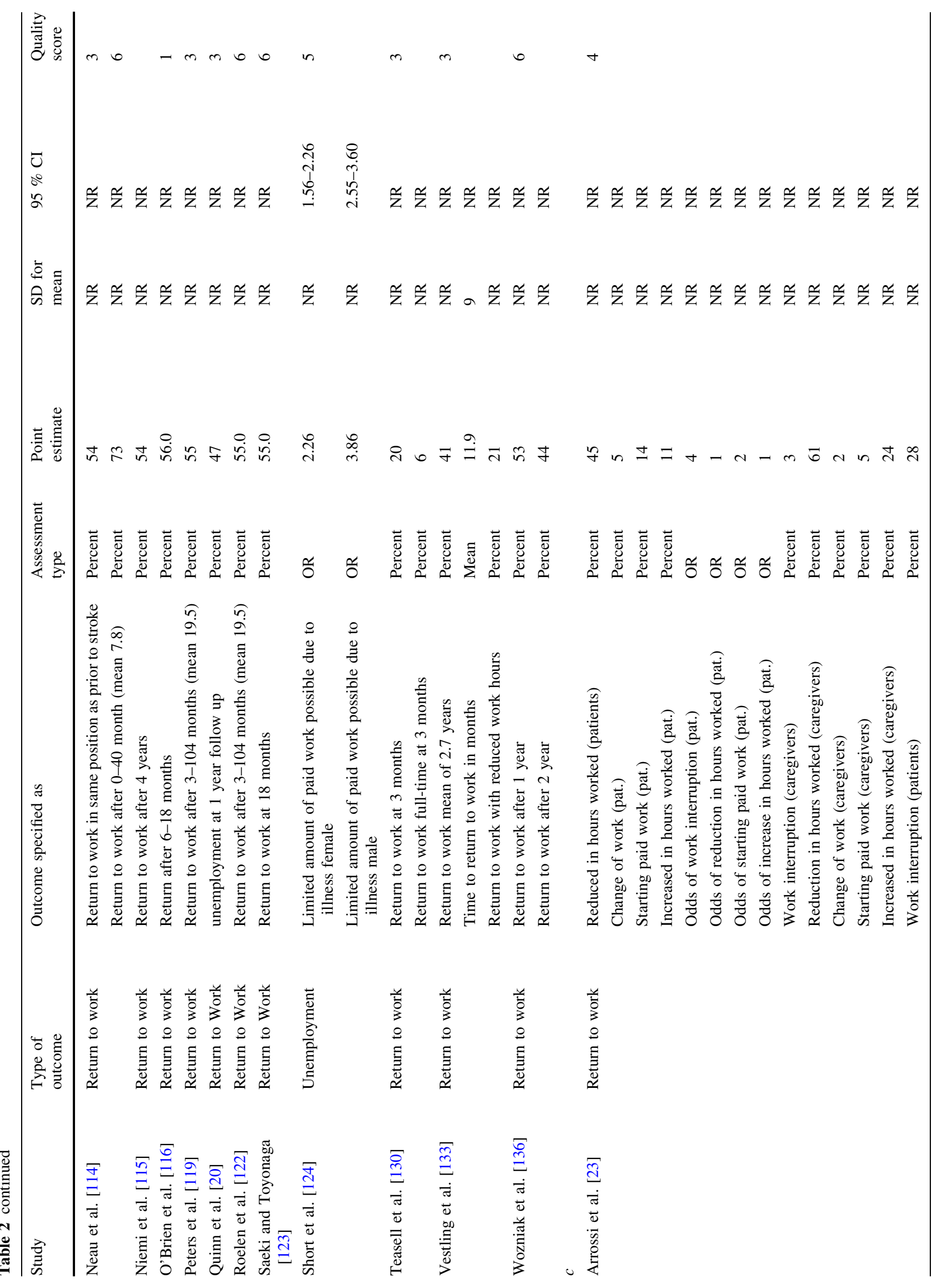




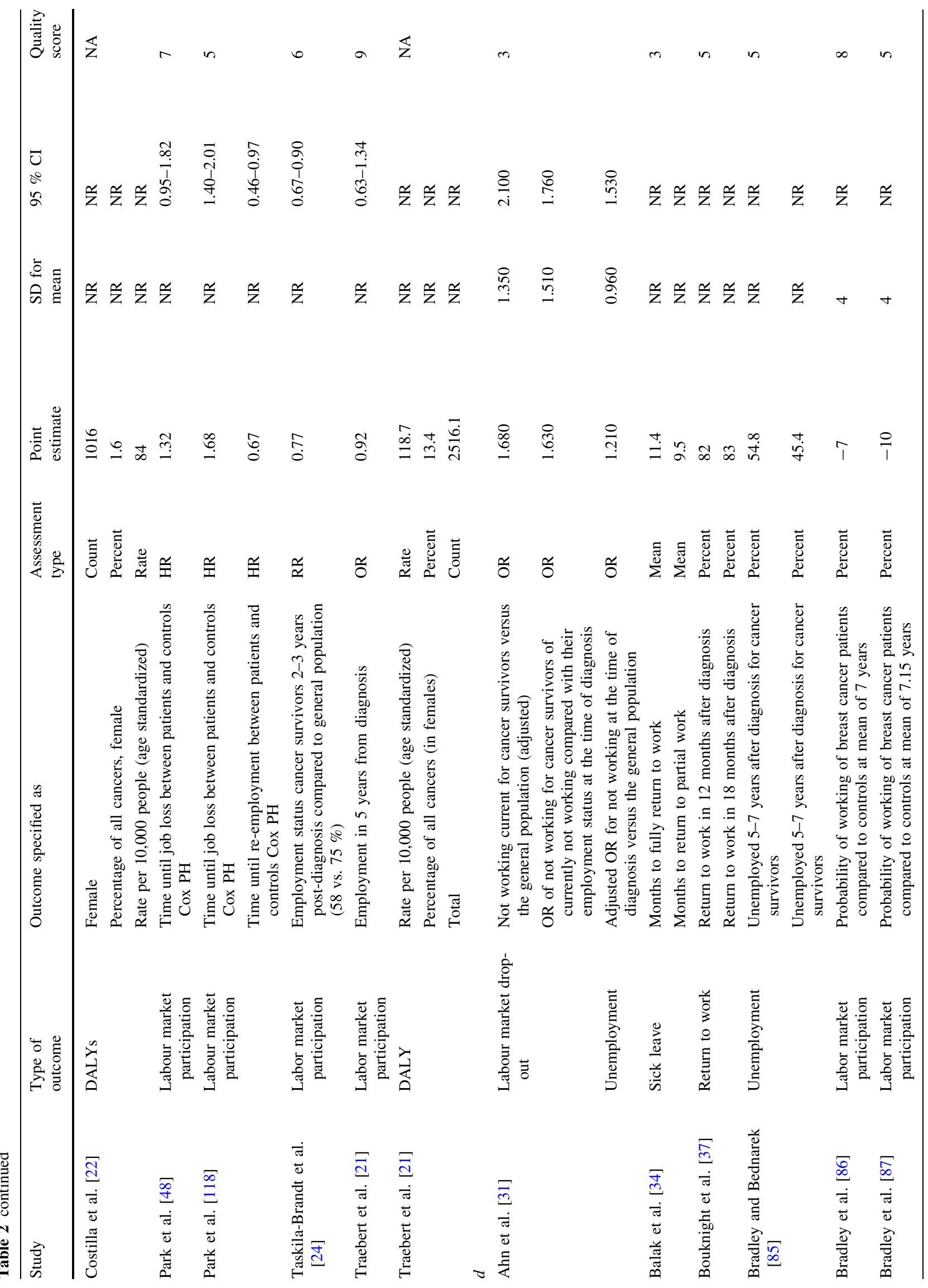




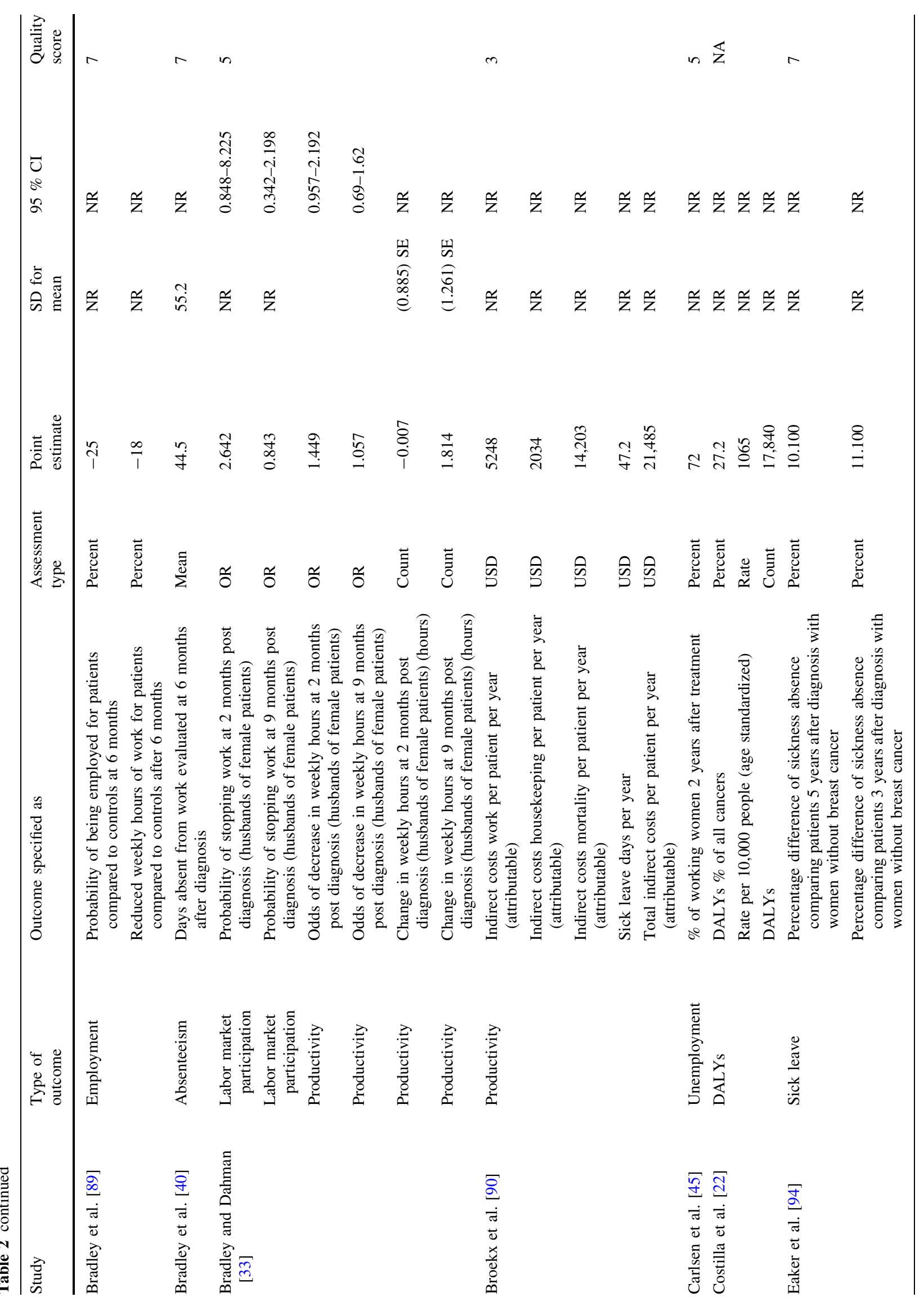




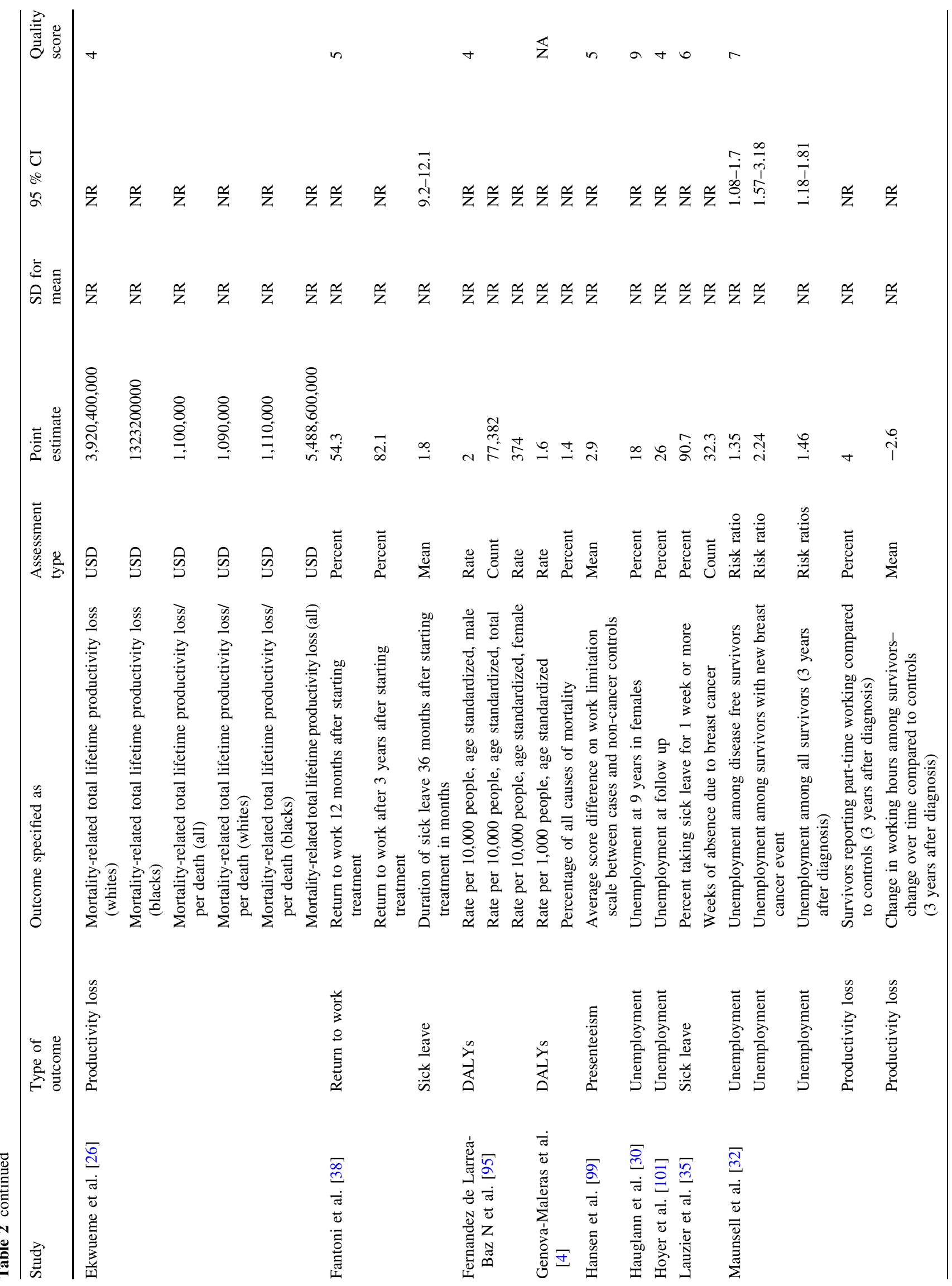




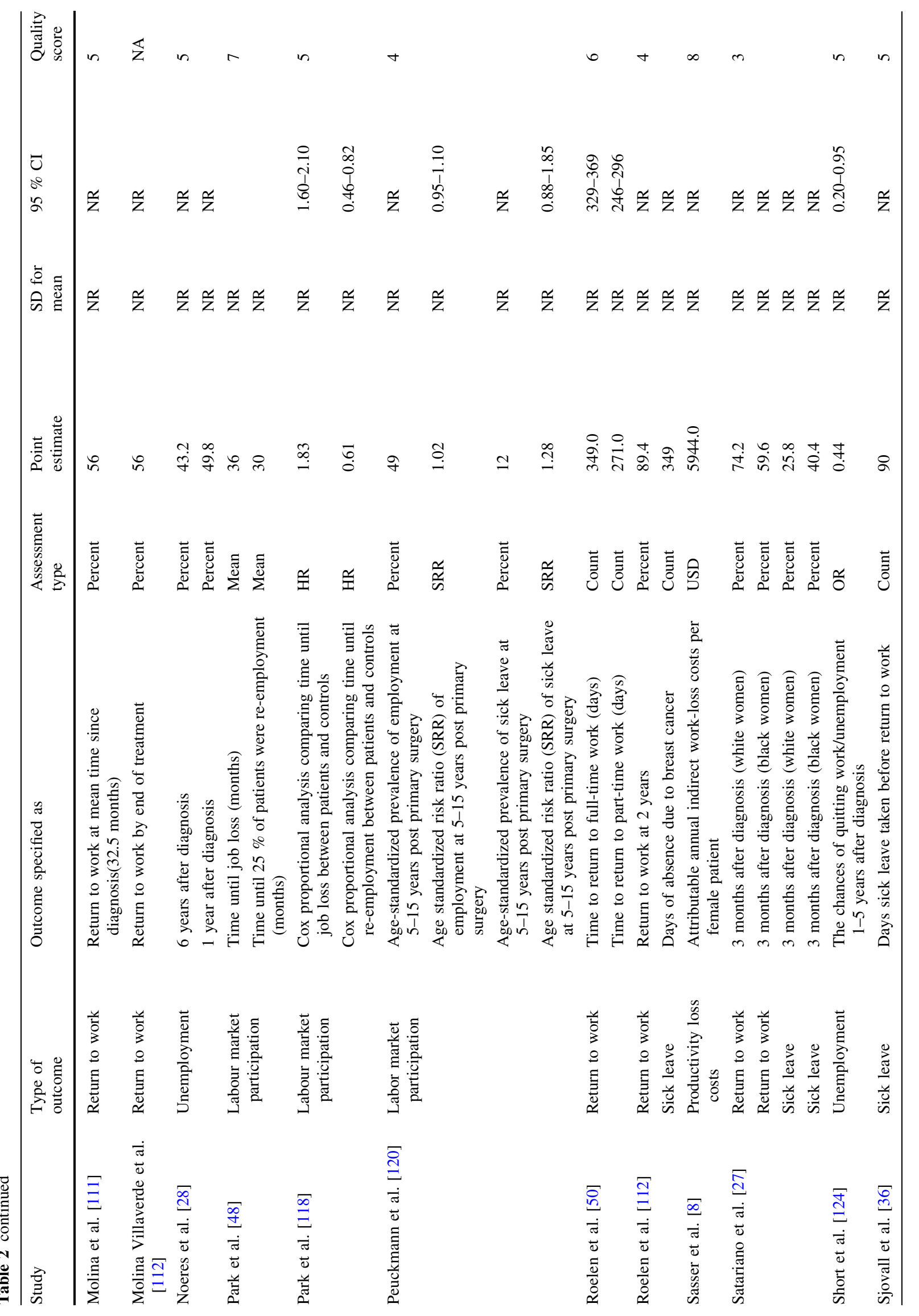




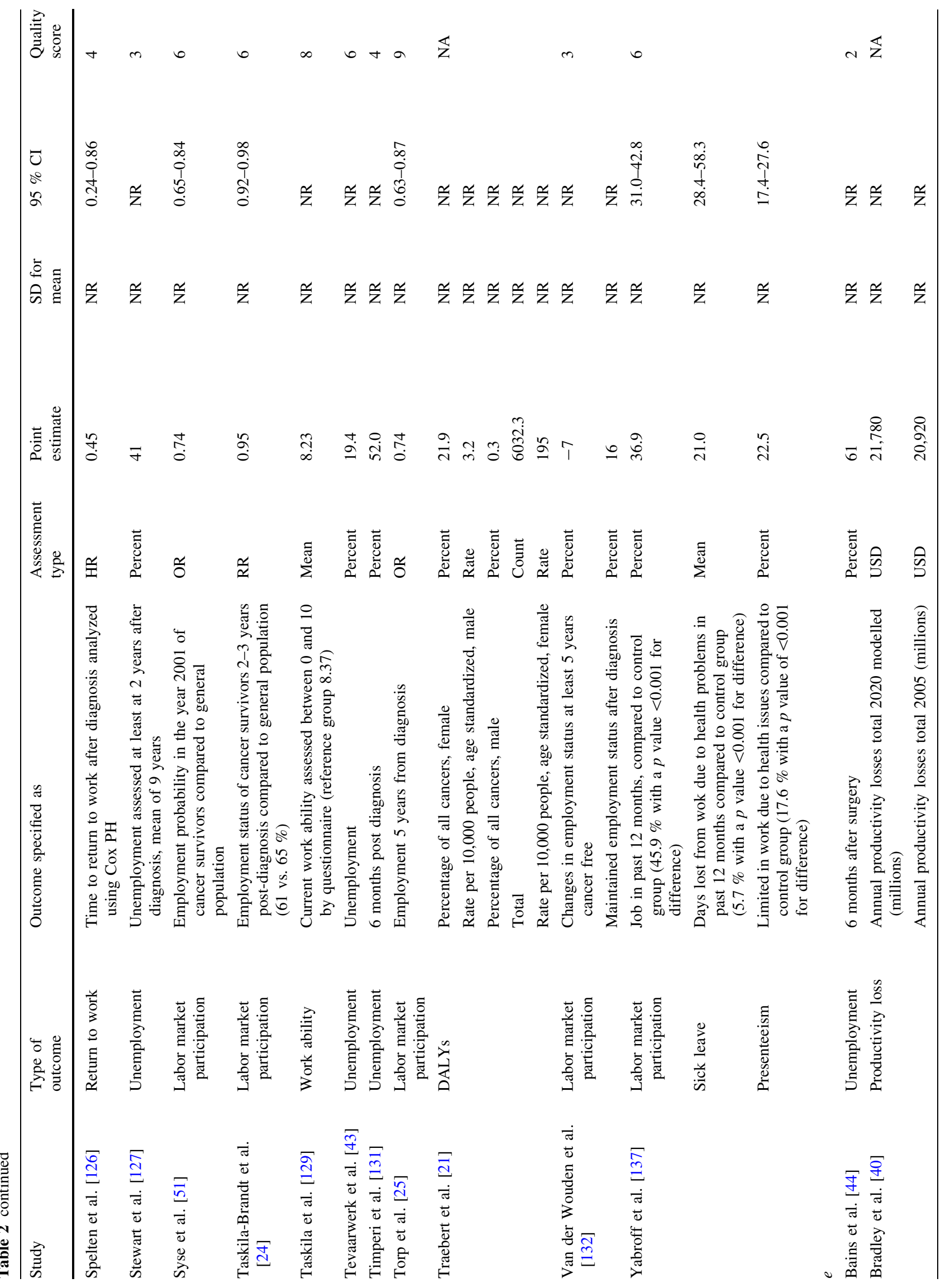




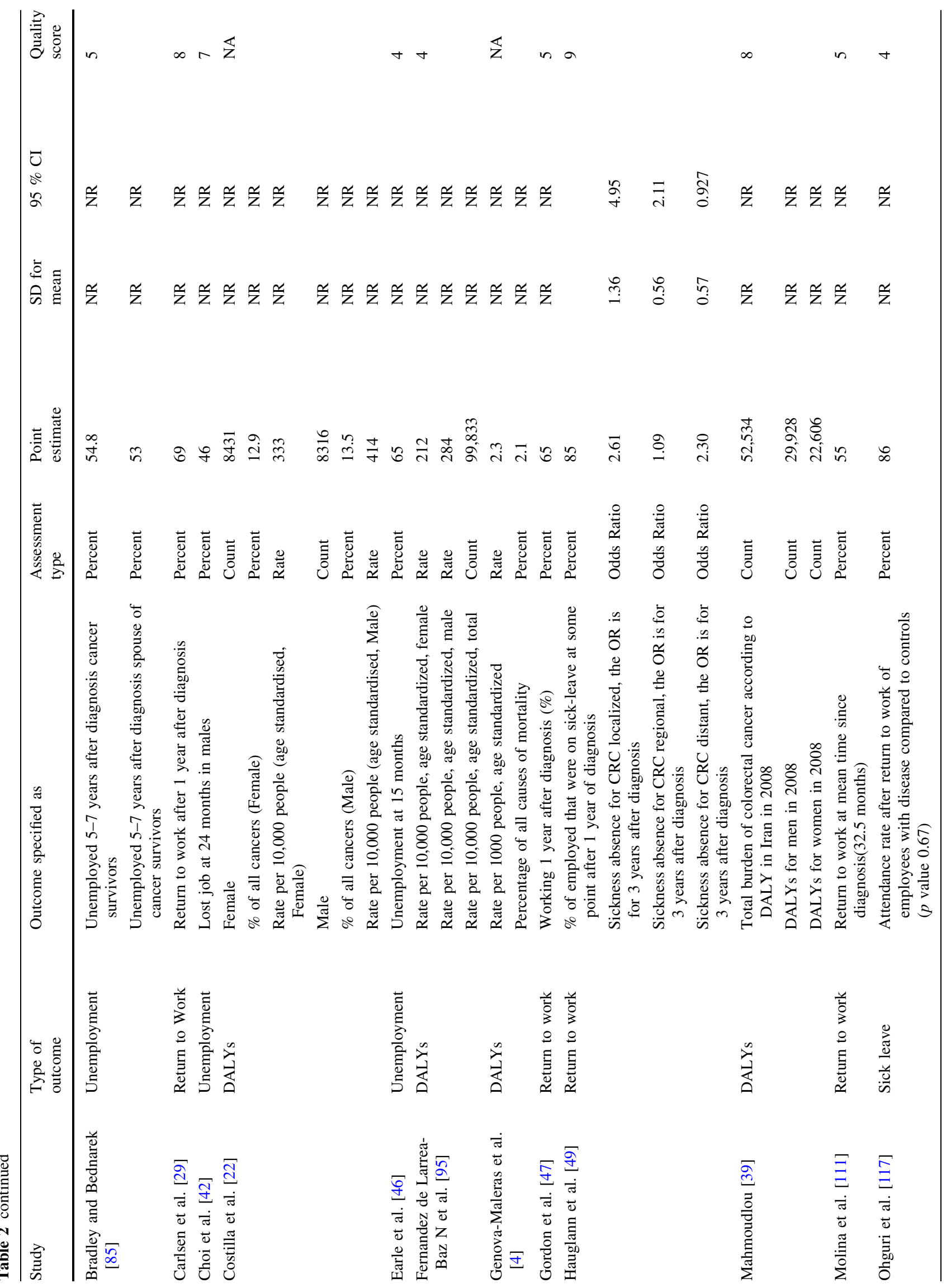




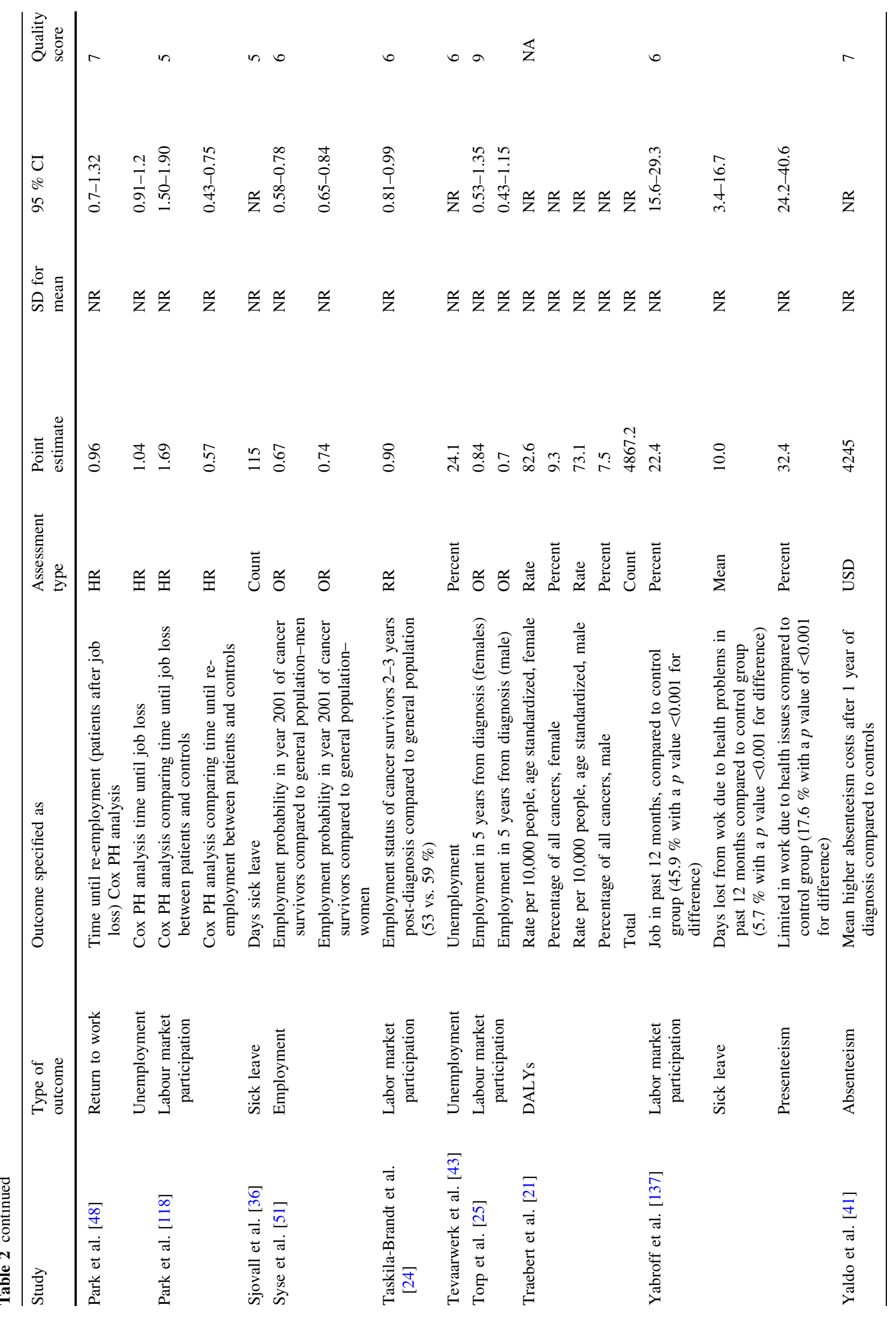




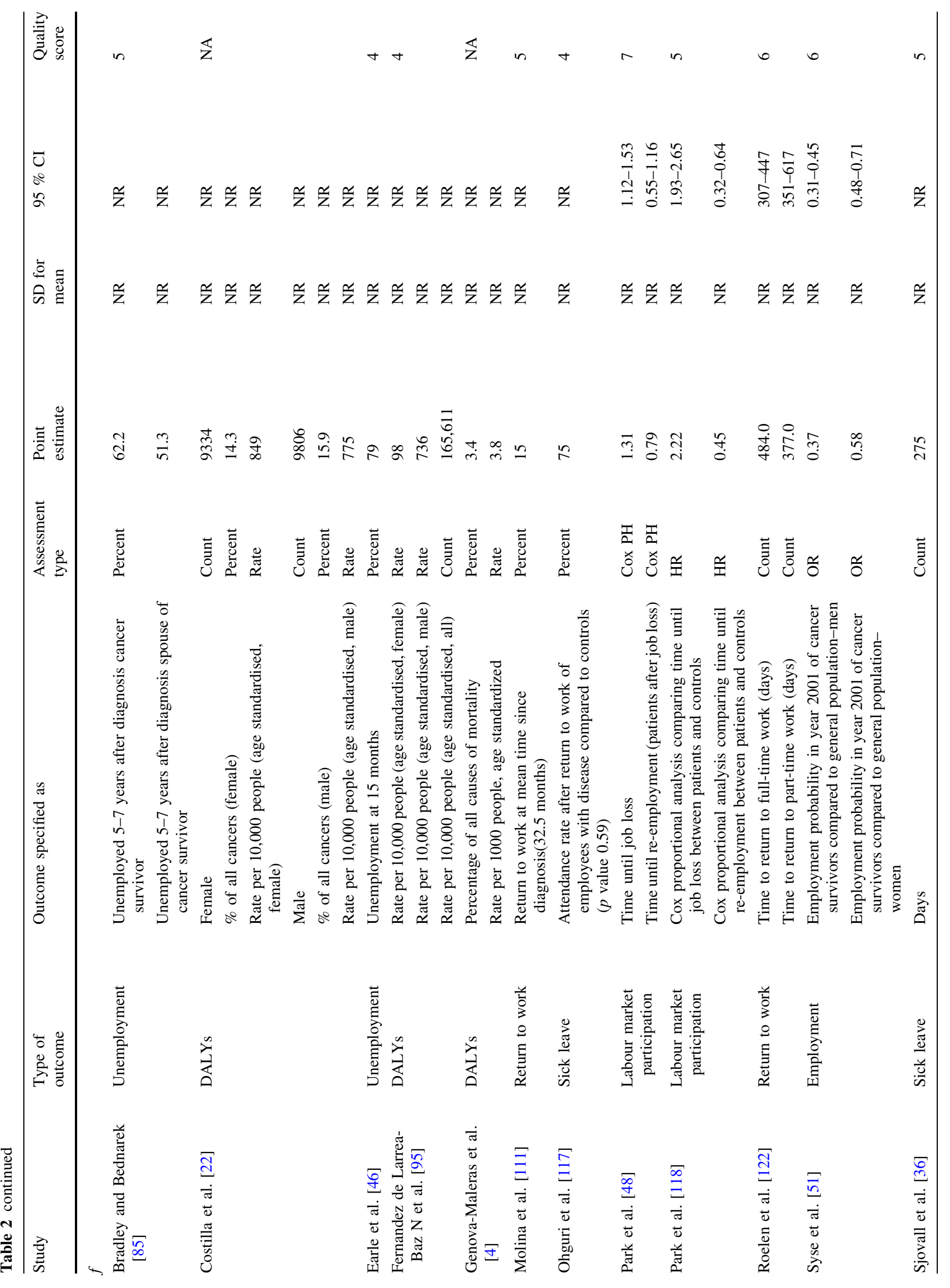




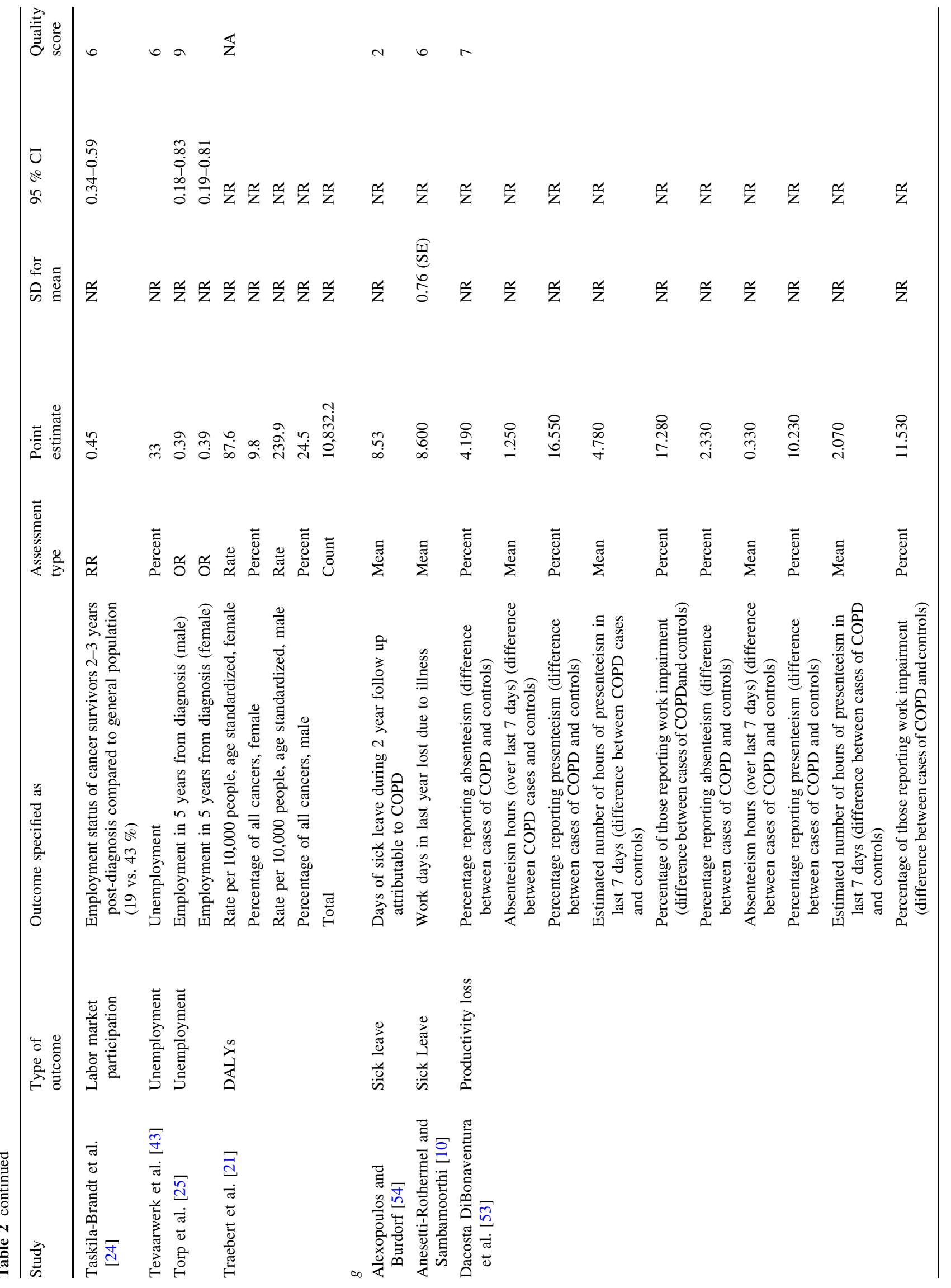




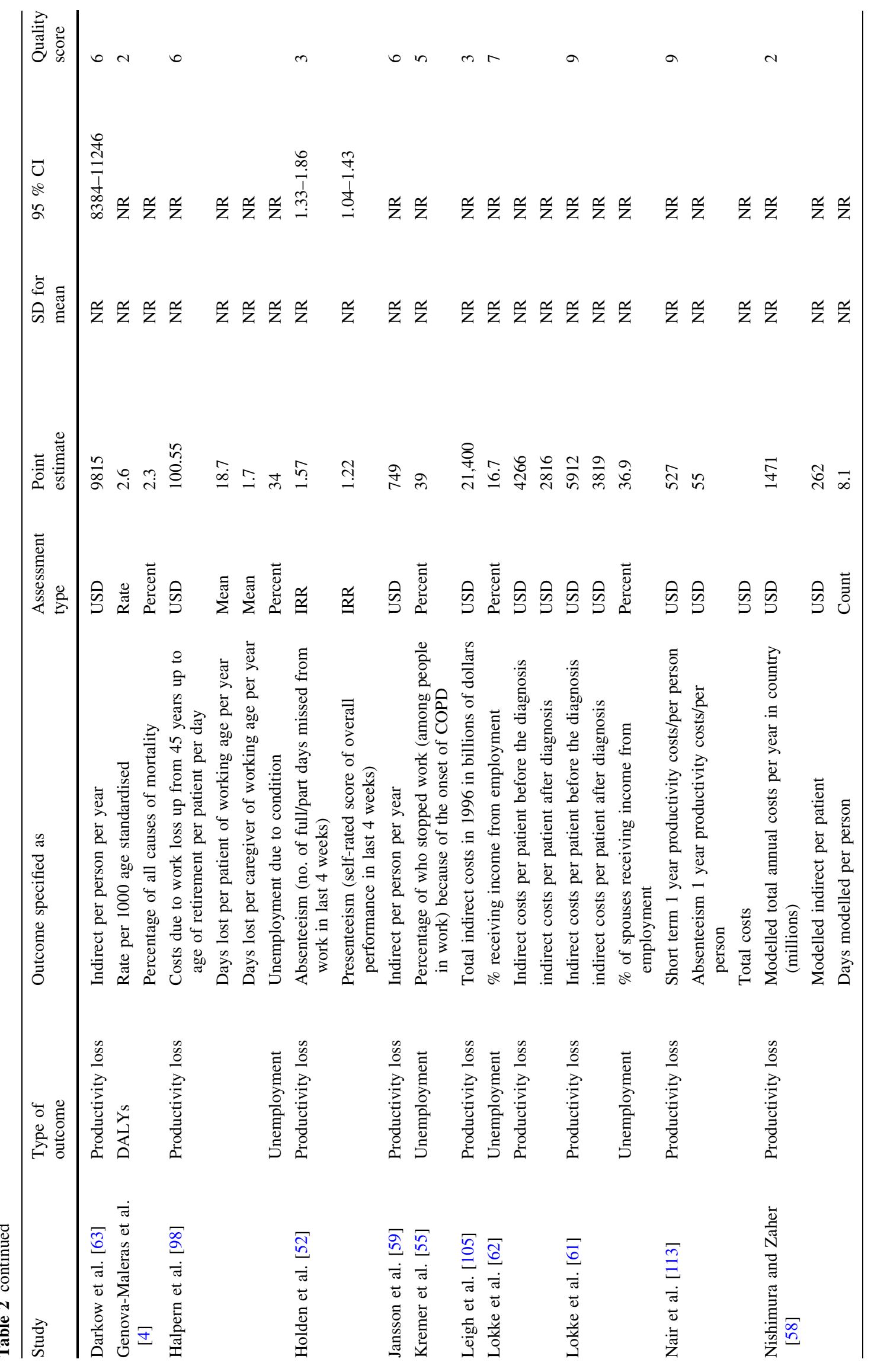




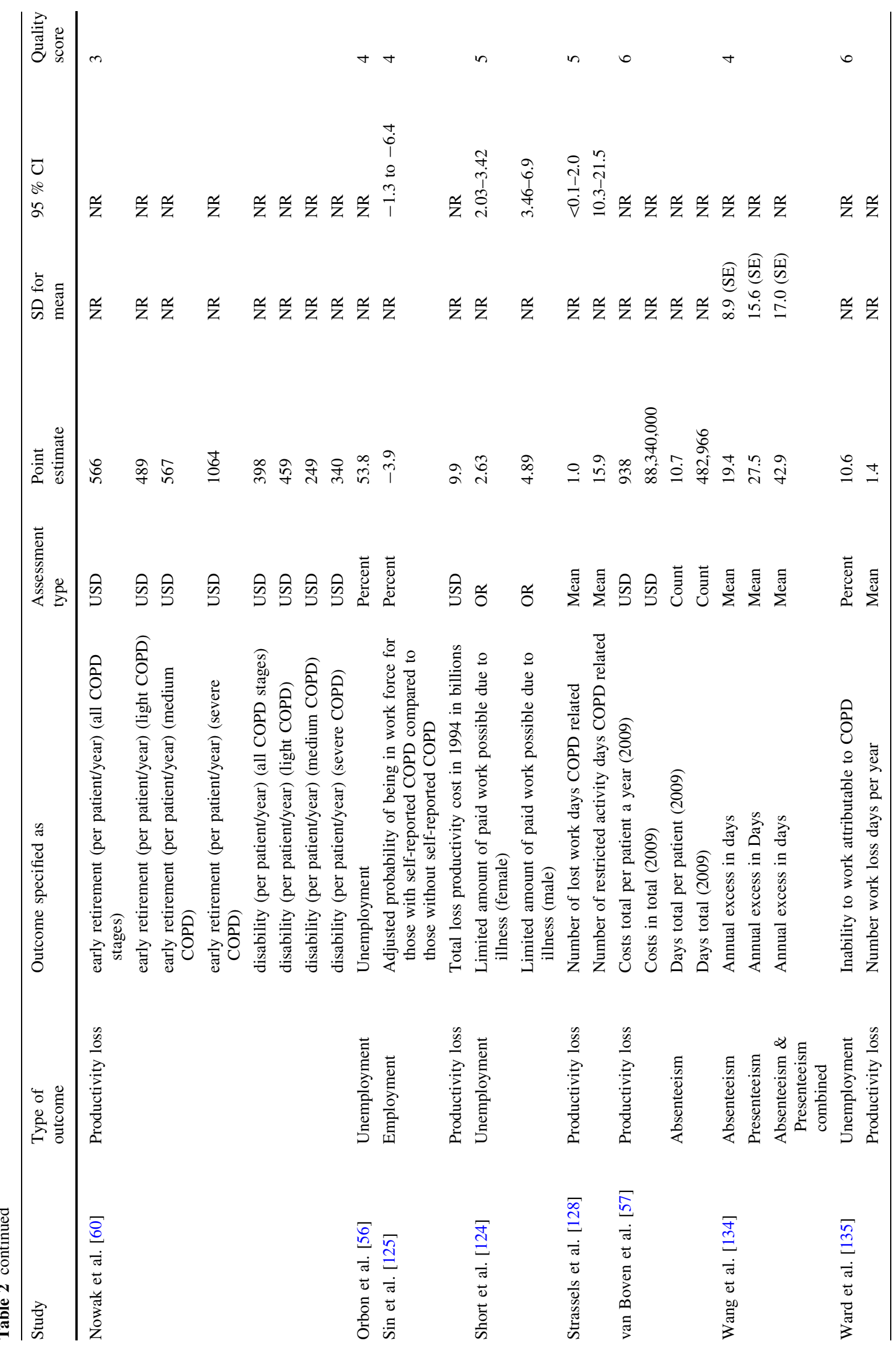




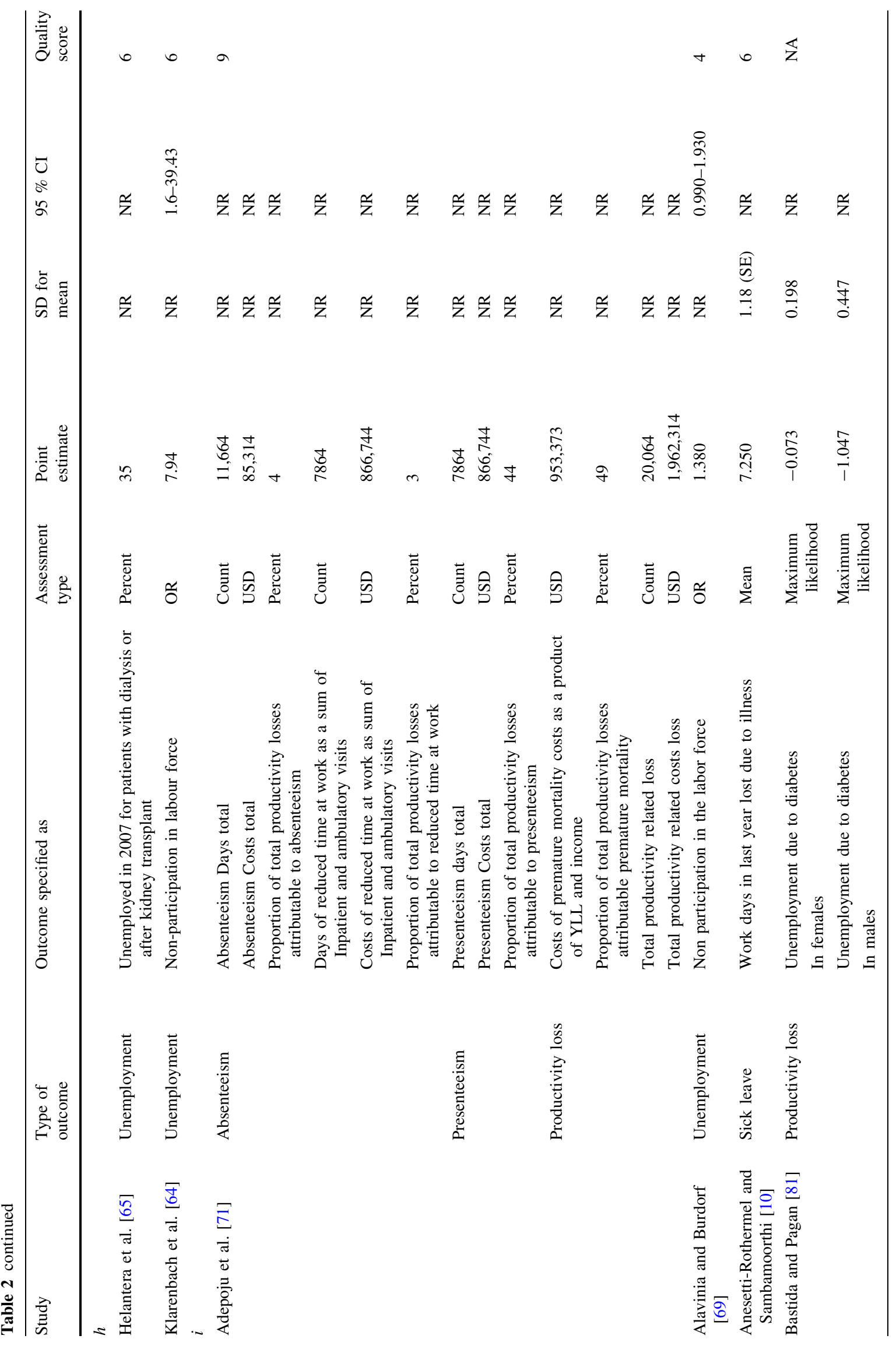




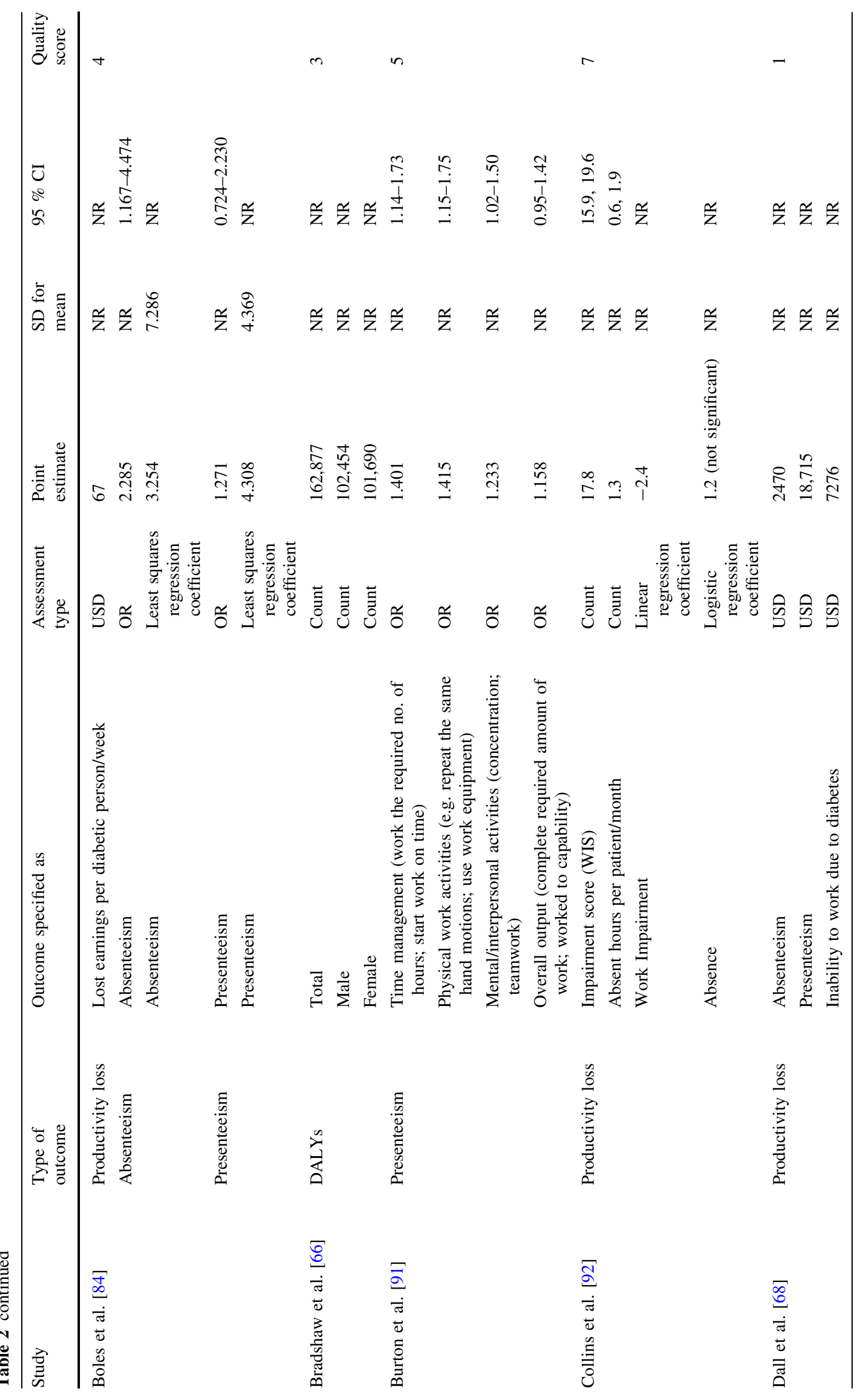




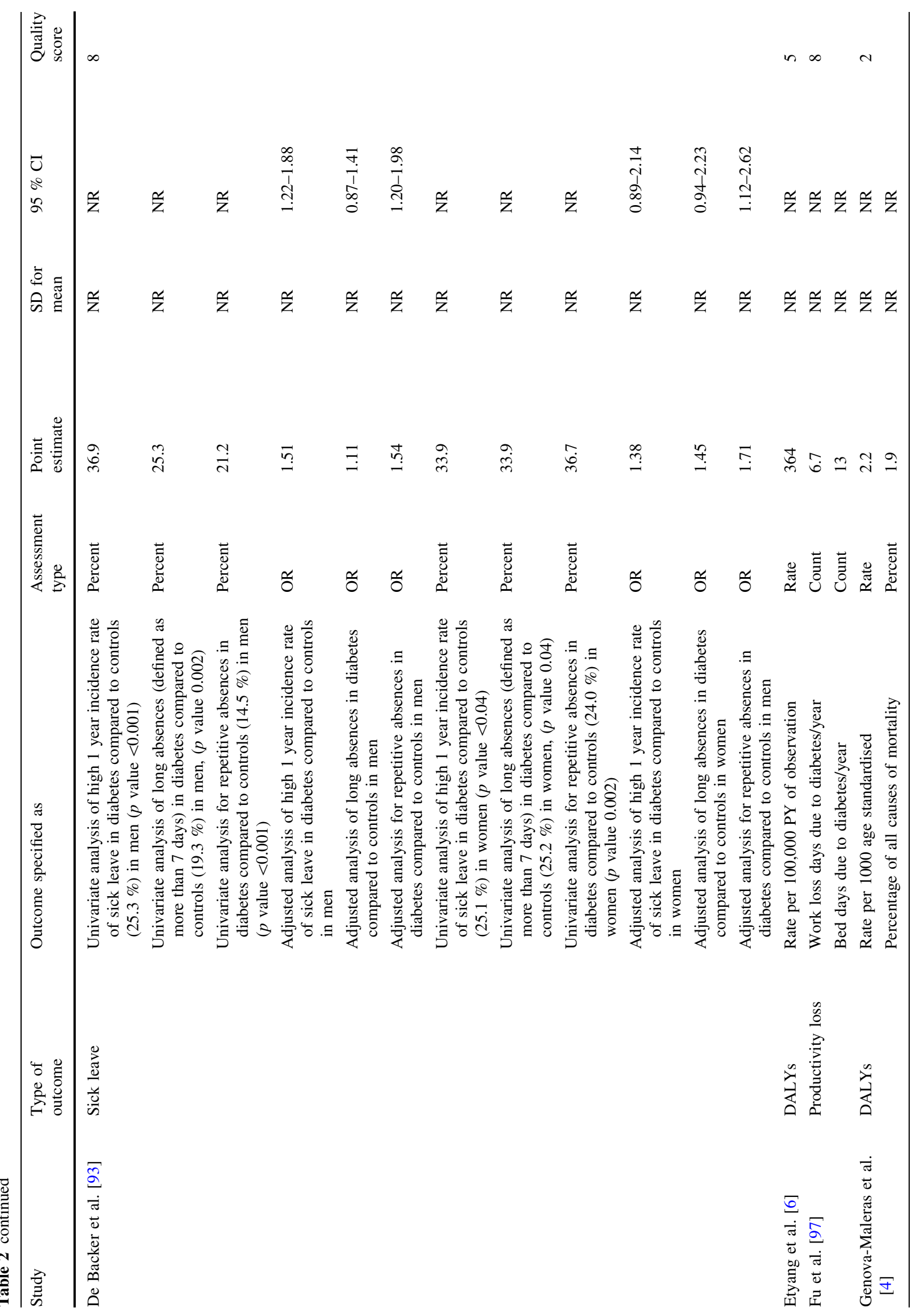




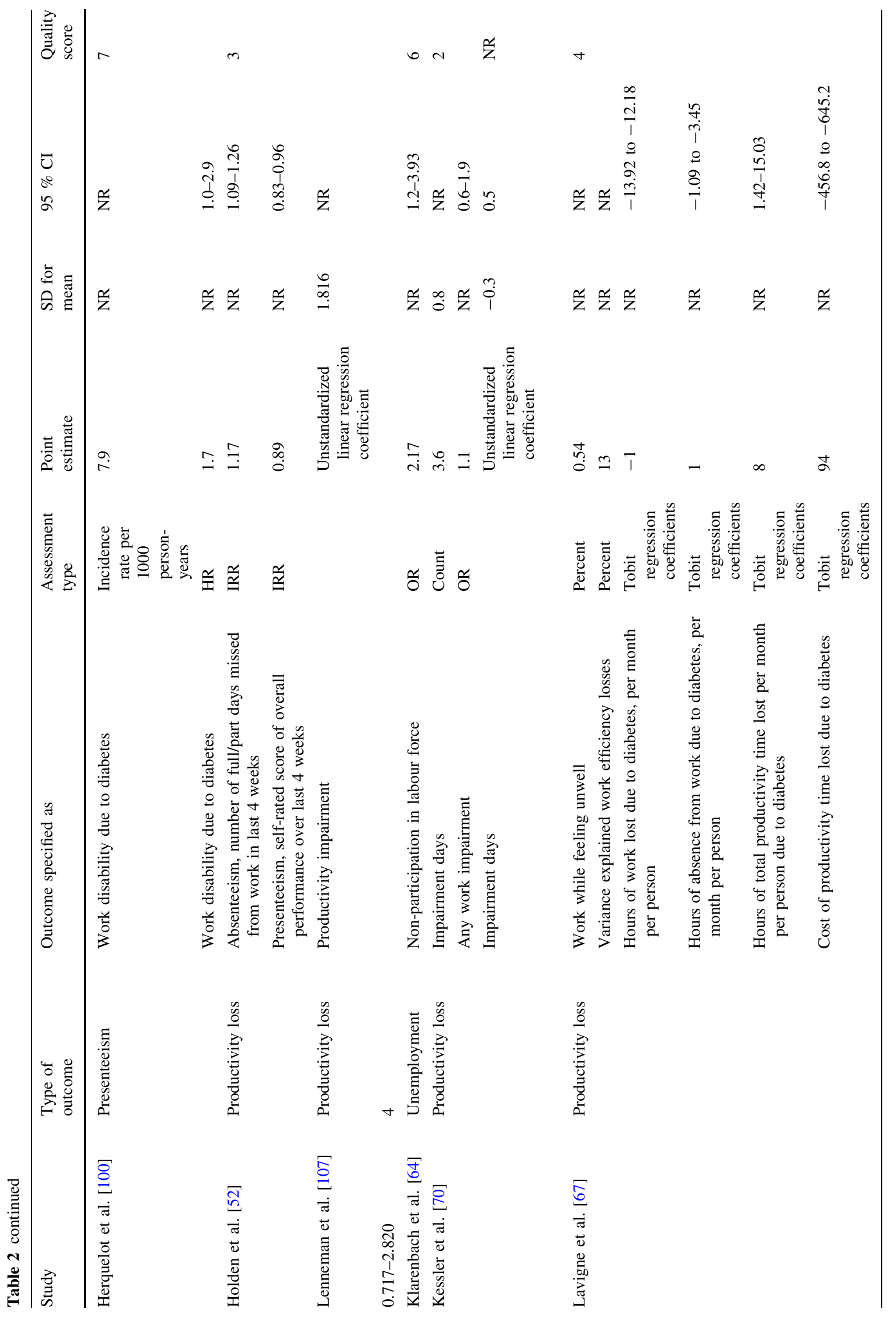




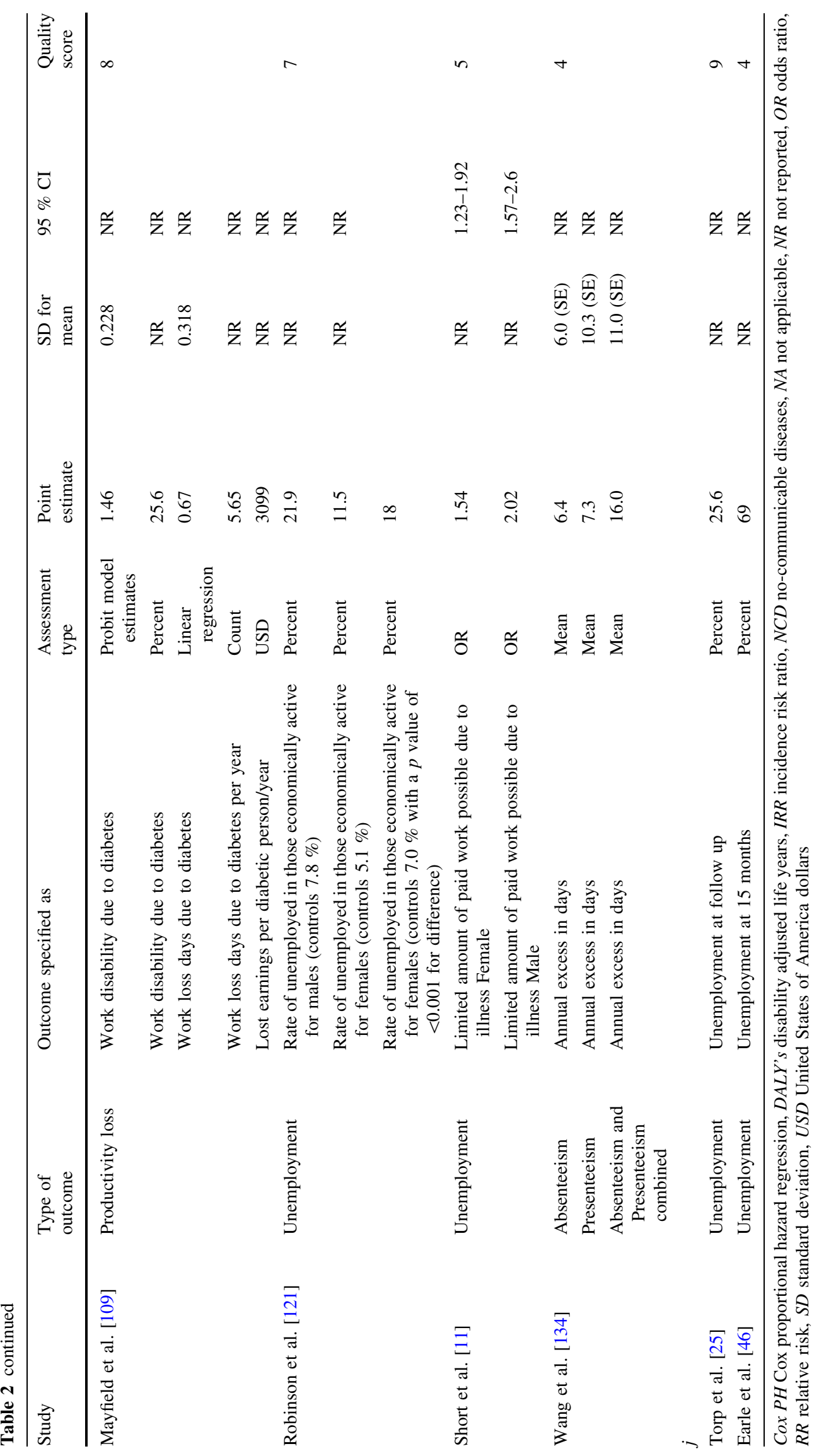




\section{Impact of cervical cancer on productivity}

There are strong regional differences in the percentage of DALYs attributable to cervical cancer (Table 2c) among women, from $1.6 \%$ (absolute DALYs, 1061 per year) in New Zealand to $13.4 \%$ (2516 per year) in Brazil [21, 22]. Cervical cancer patients in Argentina reported negative outcomes after 1 year; $45 \%$ of patients reported reduced labor market participation, $28 \%$ experienced work interruption and $5 \%$ changed work [23]. Compared to the general population, the relative risk (RR) for cervical cancer survivors in labor force participation was 0.77 (95 \% CI 0.67-0.90), 2-3 years after diagnosis in Finland [24]. In Norway however, no differences were found 5 years from diagnosis with an OR of $0.92(0.63-1.34)$ [25].

\section{Impact of breast cancer on productivity}

Of all the DALYs attributable to cancers among women, $27.3 \%$ (17,840 per year) in New Zealand (Table 2d) and $13.4 \%$ (6280 per year) in Brazil are attributable to breast cancer $[21,22]$. Total mortality-related lifetime productivity loss costs in the USA were estimated to be 5.5 billion USD [26]. This was differentially distributed between the two ethnic groups reported, with $71 \%$ (or 3.9 billion USD) of the costs attributable to white women and $24 \%$ (or 1.3 billion) attributable to black women. Differential RTW and sick absence rates are also observed comparing black and white women in the USA; the percentage of white women returning to work three months after diagnosis was $74.2 \%$ compared to $59.6 \%$ of black women; the proportion reporting sick leave was $25.8 \%$ of white women compared to $40.4 \%$ of black women [27]. 1 year after primary surgery in Germany, nearly three times as many cancer survivors had left their job as compared to women in the control group. [28] Various studies suggest higher unemployment among breast cancer survivors, reported by around half after 1 year, $72 \%$ after 2 years [29], $43 \%$ after 6 years and $18 \%$ after 9 years [27, 28, 30-32]. In contrast, in a study assessing unemployment among the spouses of breast cancer patients, no differences were found [33]. Differences between countries in average time to RTW were also found, from 11.4 months in the Netherlands [34] and 7.4 months in Canada [35] to only 3 months in Sweden [36]. Percentage of RTW after 1 year ranged from $54.3 \%$ in a cross-sectional study from France to $82 \%$ in a prospective study from the USA $[37,38]$.

\section{Impact of cancer on productivity}

In New Zealand, of all the DALYs attributable to cancers, $12.9 \%$ (8431 per year) among women and $13.5 \%$ (8316 per year) among men are attributable to colon cancer (Table 2e) [22]. In Brazil, these proportions are $9.3 \%$ among women and $7.5 \%$ among men [21]. In Spain, $2.1 \%$ of DALY's overall are attributable to colon cancer [4]. In Iran the total burden of colorectal cancer in 2008 was 52,534 DALYs and higher for men than for women [39]. In the USA, annual productivity losses were calculated to be 20.9 billion USD [40], while costs due to absenteeism after 1 year of diagnosis was 4245 USD per patient compared to the general population [41]. Although the DALY and dollar costs of colon cancer are undoubtedly large, the evidence for micro-level labor market indicators including risk and proportions of RTW, sickness absence and employment following diagnosis and treatment is however inconclusive [25, 42-49]. In New Zealand, of all cancer-attributable DALYs, $14.4 \%$ (9334 per year) among women and $15.9 \%$ (9806 per year) among men are attributable to lung cancer (Table 2f) [22]. In Brazil, lung cancer results in an estimated 10,832 DALYs per year, $9.8 \%$ of all cancer-related DALYs among women and $24.5 \%$ among men [21]. In Spain, $3.4 \%$ of all DALYs are attributable to lung cancer [4]. Most of the first year of disease ( 275 days) is spent in sickness absence in Sweden [36] and between 33 and $79 \%$ of lung cancer patients in the USA were unemployed 15 months after diagnosis $[43,46]$. Average time to re-enter the labor market was 484 days for full-time work and 377 for parttime work in the Netherlands [50]. The odds of re-entry into the labor market were significantly lower for lung cancer than the general population $[24,25,51]$.

\section{Impact of COPD on productivity}

COPD patients have a higher chance of working fewer hours, of absenteeism and of poorer work performance (presenteeism) (Table 2g). [11, 52, 53]. A COPD patient loses around 8.5 workdays per year due to disease [10,54]. Between 39 and $50 \%$ of people stopped working due to the onset of COPD in the Netherlands [55, 56]. COPDrelated productivity losses cost the US economy around 88 million USD or around 482,966 working days per year [57]. Modeled annual costs of COPD, estimated at 1.47 billion USD [58], are higher in Japan than the USA. The productivity loss costs PP/PY were somewhat comparable between Germany, Sweden and the Netherlands (566, 749 and938 USD respectively) [57, 59, 60], but differed fourfold to estimated costs in Denmark (2816-3819 USD) [61, 62] and more than tenfold to what was estimated (9815 USD) in the USA [63]. In the USA, 8.5 work days are lost PP/PY on average [10], while COPD patients take an estimated 8.6 days of sickness absence in the Netherlands during a 2 year follow-up period [54]. Also in the Netherlands, $39 \%$ of COPD patients left the labor force due to disease onset [55]. 


\section{Impact of chronic kidney disease on productivity}

Only two studies (Table $2 \mathrm{~h}$ ) examined the impact of CKD on productivity. One found that renal dysfunction was independently associated with labor force non-participation, with an odds ratio of 7.94 (95\% confidence interval, 1.60-39.43) [64]. The second study, evaluating labor market participation in CKD patients specifically after dialysis or transplantation, found that $35 \%$ of these CKD patients were unemployed [65].

\section{Impact of diabetes mellitus on productivity}

In Spain, nearly $2 \%$ of all mortality-related DALYs are attributable to DM [4]. In South Africa, 162,877 DALYs annually are attributable to DM (Table 2i) [4, 66]. A study from Kenya reports a rate of 364 DALYs per 100,000 observed person-years [6]. An estimated 7.2 days are lost PP/PY due to DM in the USA [10] and DM patients have an increased risk of absenteeism, presenteeism and inability to work [4, 10, 11, 52, 64, 67-69]. Productivity days lost per year due to diabetes ranged from 3.6 to $7.3[10,70]$. In the USA, proportion of productivity loss was large due to premature mortality (49\%) and presenteeism (44\%) compared to absenteeisim (4\%) and total productivity related costs were estimated to be 1,962,314 USD [71]. The odds of non-participation of the labor force for diabetes patients compared to the general population were slightly higher with borderline significance in the EU, an OR of 1.38 (95\% CI 0.99-1.93) [69].

\section{Discussion}

This systematic review identified 126 studies investigating the impact of NCDs on productivity. Most studies (96\%) were from the Western world (North America, Europe or Asia Pacific), with limited evidence available from Brazil, South Africa, Kenya, Tanzania, Iran, Japan, South Korea and Argentina. Macro-economic productivity losses were measured in percentage and absolute numbers of DALYs and annual productivity loss costs (in USD). Studies also estimated productivity losses using labor market indicators including unemployment, RTW, absenteeism, presenteeism, sickness absence and loss in working hours. There is a clear scarcity in literature concerning the effect of CKD on productivity, with only two studies both reporting a substantial impact on productivity [64, 65].

\section{Diversity in the macroeconomic measures and outcomes}

There were considerable global differences in the NCDattributable DALY burden, especially the differential impact of each NCD comparing high-income countries (HIC) and low- and middle-income countries (LMIC). Lung and colon cancer account for nearly $30 \%$ of all cancer-attributable DALYs in men in New Zealand whereas in Brazil, lung cancer alone accounts for nearly $25 \%$. Among women in HIC, breast cancer seems to impose a large productivity burden whereas cervical cancer impacts more dramatically in LMIC [4, 21, 22]. Although DALYs are a reliable measure and capture both years of life lost and years spent in ill-health, we found inconsistent application in the identified studies; some estimated proportions within specific disease groups or of the overall DALY burden in a country; others estimated absolute DALY numbers.

\section{Diversity in the macro-economic impact of the cardiopulmonary diseases}

Absolute costs (measured in USD) were estimated for COPD, CHD, and stroke events [7, 9, 15, 57, 58, 71]. These studies mainly came from HIC, although two studies, one from Kenya and one from Tanzania, were also retrieved. In Australia, absenteeism and lower employment due to CHD cost 13.2 billion USD annually, as well as an additional 23 million USD in mortality-related costs [9]. Evidence suggests that COPD costs around 88 million USD or nearly 500,000 working days per year in the US compared to 1.47 billion (modeled) in Japan. While annual COPD-related productivity costs were comparable in Germany, Sweden and the Netherlands (between 566 and 938 USD), costs differed fourfold (2816-3819 USD) in Denmark, tenfold (9815 USD) in the USA [57, 59-63]. In the USA, nearly half of the annual $1.96 \mathrm{~m}$ USD productivity losses due to DM are attributable to mortality, with $44 \%$ attributable to presenteeism and just $4 \%$ to absenteeism In South Korea, modeled productivity losses for a stroke were $68 \%$ higher among men compared to women [16]. Around half of all stroke survivors in unemployed after 1 year [20]. In Tanzania, productivity losses after 6 months following stroke were 213 USD on average although these losses were most acutely experienced by those in higher skill roles [17]. Interestingly, indirect productivity losses were higher among caregivers than stroke patients themselves and costs increased for caregivers but declined for patients after 1 and 2 years following a stroke in Spain. COPD patients experience reduced working hours, unemployment, absenteeism and presenteeism [10, 11, 52-56]. DM patients also have an increased risk of reduced labor market participation [10, 11, 52, 64]. By contrast, other than for absenteeism [10] the evidence for the risk of reduced labor market participation due to CVD is inconclusive. In Kenya, 68/100,000 person year observed are attributable to CVD compared to $166 / 100,000$ for stroke and 364/100,000 for 
DM [6]. Although evidence is limited, the higher productivity impact associated with diseases with a large morbidity was perhaps to be expected; chronic diseases such as COPD and DM affect people during their productive years and cannot really be 'cured', only managed. The extent to which employers or societies support and enable NCD populations to remain members of the productive workforce will also differentially distribute the impact. The extent to which secondary or tertiary prevention is possible will also affect productivity estimates, specifically so for labor market indicators such as RTW, change in work status or unemployment.

\section{Diversity in the macroeconomic impact of cancer}

Lung cancer survival is associated with reduced labor market participation through sickness absence, extended RTW [36, 50] and unemployment [25, 43, 46]. Total mortality-related lifetime productivity loss due to breast cancer were an estimated 5.5 billion USD in the USA [26] and annual productivity losses due to colon cancer costs the US economy 20.9 billion USD [40]. We found inconclusive evidence of risk of reduced labor market participation (RTW, sickness absence and unemployment) following colon cancer diagnosis and treatment [25, 42-46, 48]. The evidence for breast cancer-related labor market drop-out shows higher unemployment among survivors 1, 2, 6 and 9 years after diagnosis [29-32]. Evidence from the USA also suggests ethnicity-patterned differences in sick leave and unemployment [27]. Along with possible socio-economic differences associated with these outcomes [72], pathophysiological differences may also play a role. African-American women have lower incidence of breast cancer but higher mortality and are also diagnosed in later stages and with more aggressive types of tumors [73]. However, we are cautious in over interpretation of this finding as few studies included ethnicity. Geographic differences in average months to RTW were observed from 11.4 in the Netherlands [34] to 7.4 in Canada [35] to just three months in Sweden [36].

Although evidence is limited, the higher productivity impact associated with diseases with a large morbidity was perhaps to be expected; chronic diseases such as COPD and DM affect people during their productive years and cannot really be 'cured', only managed. It is surprising that half of all productivity losses in the USA attributable to DM are due to mortality rather than absenteeism and presenteeism. The extent to which employers or societies support and enable NCD populations to remain members of the productive workforce will also differentially distribute the impact both within societies but also comparing more affluent to less affluent countries. The extent to which secondary or tertiary prevention is possible will also affect productivity estimates, specifically so for labor market indicators such as RTW, change in work status or unemployment.

\section{Comparison with the previous work}

Findings of this systematic review generally concur with and further extend the previous reviews. This study is a comprehensive systematic review tackling work-related burden of six major NCDs using a global perspective and without language limitation. Two reviewers included and assessed the studies and references of the included studies were tracked for any missing evidence. These approaches ensured that we included most of the relevant articles in our review. Similar to previous reviews, we found that, due to a great amount of variation in the studies included, comparability and pooling the studies were not possible. Most of the previous reviews were performed non-systematically and previous systematic reviews have included studies only in English. Previous studies were mainly focused on the impact of cancers [74-78] on work-related outcomes (mainly RTW) and often included a mix of cancers without specifying the type of cancer. Van Muijen and colleagues [78] reviewed only cohort studies of cancer-related work outcomes and were focused on English language. Steiner and colleagues [76] reviewed English publications published up until 2003, Breton and colleagues were focused only on diabetes and Krisch and colleagues focused on COPD in Germany [79].

\section{Strengths and limitations of the current work}

In this systematic review we evaluated the literature concerning the impact on productivity of six top NCDs. These six were selected based on their dominance in the global burden of disease and together make a huge contribution to mortality and morbidity worldwide. Several important issues are out of scope for this work but do merit future research. First, we did not look into the underlying mechanisms of what forces people with NCDs in and out of the labor force, specifically in terms of co-morbidities (certain NCDs cluster in the same populations) and financial/social means available at an individual and collective level. How these mechanisms interact will also be different according to the level of economic and social development. For example, children in LMIC are more likely to be forced into the labor market due to the onset of NCDs in parents compared to children in HIC and the productive output of this child cannot replace the loss due to drop out by the parents. These related topics should be addressed separately to better understand how to modify and target these outcomes more specifically. Second, we observed wide heterogeneity in all domains within the studies 
selected, including study design, methods and sources used to measure productivity, adjustment for confounders and analyses. Third, no identified studies quantified the differential productivity impact by national economic development and labor market structure across countries. How these inter-country macro-economic differences might mitigate or magnify productivity losses associated with NCDs is worth further exploration. Fourth, we identified a crucial gap of relevant information from LMICs-limiting the relevance of our review most acutely in these settings. This lack of evidence could reflect differences in disease burden, in research capacity, in welfare systems and in epidemiological surveillance. The burden of NCDs is growing rapidly in LMIC; countries that often lack capacity in these key areas of support, prevention and knowledge generation. Further evaluation, therefore, of the macro-economic impact in the LMIC countries is urgently needed. Also, many NCDs affect people cumulatively over time; people may suffer DM, may experience absenteeism/ presenteeism as a result, may reduce work as DM worsens and may finally drop out of the workforce due a stroke or CHD, which is related to the DM. Given NCDs are shifting more and more into chronic conditions, as our understanding of treatment and natural history improve, it would be of great interest to investigate the effects over the life course rather than using short time horizons such as a year. This is no mean feat, but could be crucial for developing a better understanding of the economic impact of NCDs on a regional, national and international level. Also out of scope for this review but of interest for future work are the productivity-related impact of behavioural risk factors that contribute to the development of NCDs.

\section{Conclusions}

In summary, available studies indicate that the six main NCDs generate a large impact on macro-economic productivity in the WHO regions. However, this evidence is heterogeneous, of varying quality and not evenly geographically distributed. Data from LMI countries in economic and epidemiological transition are virtually absent. Further work to reliably quantify the absolute global impact of NCDs on macro-economic productivity and DALYs is urgently required.

Acknowledgments Completion of this manuscript was supported by a grant from the WHO. O. H. Franco and L. Jaspers work in ErasmusAGE, a center for aging research across the life course funded by Nestlé Nutrition (Nestec Ltd.); Metagenics Inc.; and AXA. Nestlé Nutrition (Nestec Ltd.); Metagenics Inc.; and AXA had no role in design and conduct of the study; collection, management, analysis, and interpretation of the data; and preparation, review or approval of the manuscript. Dr. Shanthi Mendis from the WHO and co-author on this manuscript participated in the interpretation and preparation of this manuscript. The manuscript was approved by the WHO for submission.

Conflict of interest With regard to potential conflicts of interest, there is nothing to disclose. Drs. Chaker, van der Lee, Falla and Franco had full access to all the data in the study and take responsibility for the integrity of the data and the accuracy of the data analysis.

Open Access This article is distributed under the terms of the Creative Commons Attribution 4.0 International License (http:// creativecommons.org/licenses/by/4.0/), which permits unrestricted use, distribution, and reproduction in any medium, provided you give appropriate credit to the original author(s) and the source, provide a link to the Creative Commons license, and indicate if changes were made.

\section{Appendix 1: Search strategy up to 6th of November 2014}

('non communicable disease'/de OR 'ischemic heart disease'/exp OR 'cerebrovascular accident'/exp OR 'chronic obstructive lung disease'/de OR 'lung cancer'/exp OR 'colon cancer'/exp OR 'breast cancer'/exp OR 'chronic kidney disease'/de OR 'non insulin dependent diabetes mellitus'/de OR 'uterine cervix cancer'/exp OR ('non communicable' OR noncommunicable OR ((heart OR cardiac OR cardial OR cardiopath* OR cardiomyopath* OR coronar* OR myocard*) NEAR/3 (ischem* OR ischaem* OR anoxia OR hypoxia)) OR (coronary NEAR/3 (insufficien* OR occlus* OR disease* OR acute OR atherosclero* OR arteriosclero* OR sclero* OR cardiosclero* OR constrict* OR vasoconstrict* OR obstruct* OR stenosis* OR thrombo*)) OR angina* OR ((heart OR myocard* OR cardiac OR cadial) NEAR/3 infarct*) OR ((cerebrovascul* OR brain OR 'cerebral vascular' OR 'cerebro vascular') NEAR/3 (accident* OR lesion* OR attack OR ischem* OR ischaem* OR insult* OR insuffucien* OR arrest* OR apoplex*)) OR cva OR stroke OR (chronic AND (obstruct* NEAR/3 (lung* OR pulmonar* OR airway* OR bronch* OR respirat*))) OR ((lung* OR pulmonar* OR colon* OR colorect* OR breast* OR mamma*) NEAR/3 (neoplas* OR cancer* OR carcino* OR adenocarcino* OR metasta* OR sarcom*)) OR (chronic NEAR/3 (kidney* OR nephropathy* OR renal)) OR (('adult onset' OR 'type 2' OR 'type ii' OR 'non-insulin dependent' OR 'noninsulin dependent' OR 'insulin independent') NEAR/3 diabet*) OR ((cervix OR cervical) NEAR/3 (cancer* OR neoplas* OR tumo* OR carcinom* OR malign*))):ab,ti) AND (adult/exp) AND ('randomized controlled trial'/exp OR 'cohort analysis'/de OR 'case control study'/exp OR 'cross-sectional study'/de OR 'systematic review'/de OR 'meta analysis'/de OR ecology/exp OR 'ecosystem health'/exp OR 'ecosystem 
monitoring'/exp OR model/exp OR ((random* NEAR/3 (trial* OR control*)) OR rct* OR cohort* OR 'case control' OR 'cross-sectional' OR (systematic* NEAR/3 review*) OR metaanaly* OR (meta NEXT/1 analy*) OR ecolog* OR ecosystem* OR model*):ab,ti) NOT ([animals]/lim NOT [humans]/lim) NOT ([Conference Abstract]/lim OR [Conference Paper]/lim OR [Letter]/lim OR [Note]/lim OR [Conference Review]/lim OR [Editorial]/ lim OR [Erratum]/lim).

AND (productivity/de OR absenteeism/de OR 'job performance'/de OR 'return to work'/de OR 'work capacity'/de OR 'working time'/de OR 'medical leave'/de OR workload/de OR retirement/de OR employment/exp OR unemployment/de OR (productivit* OR unproductivit* OR absenteeis* OR presenteeis* OR ((job OR work* OR profession* OR occupation* OR labour) NEAR/3 (perform* OR efficien* OR return* OR back OR capacit* OR abilit* OR disabilit* OR unab* OR limit* OR impair* OR loss OR losing OR restrict* OR reduct* OR input*)) OR (work* NEXT/1 (time OR week* OR day* OR load*)) OR workweek* OR workday* OR ((medical OR sick) NEXT/1 leave) OR workload* OR 'time off work' OR retire* OR employment* OR employed* OR unemploy* OR daly OR ('disability adjusted' NEXT/2 year*)):ab,ti).

\section{Appendix 2: Newcastle-ottawa quality assessment scale}

\section{Cross-sectional and descriptive studies}

Note: A study can be awarded a maximum of one star for each numbered item within the Selection and Exposure categories. A maximum of two stars can be given for Comparability.

Selection

(1) Is definition of NCDs adequate?
(a) Yes, according to a clear and widely used definition*
(b) Yes, e.g. record linkage or based on self- reports
(c) No description

(2) Representativeness of the cases

(a) Consecutive or obviously representative series of cases*

(b) Excluded cases are random*

(c) No description of the excluded cases or potential for selection biases or not stated

(3) Comparison with a reference group
(a) The results are compared with a reference from community or with the status of the cases prior to the disease*
(b) The results are compared with the results from other patients
(c) No description/no comparison available

(4) Definition of reference
(a) Individuals with no NCD or sample from general population or the same individuals before NCD suffering*
(b) Non community comparator is described
(c) No description of source

\section{Comparability}

(1) Comparability of the results on the basis of the design or analysis
(a) The results are described in age and sex sub groups (sex is not applicable for female diseases)*
(b) The results are additionally adjusted for/ described in different socioeconomic factors or disease related confounders*

\section{Exposure (costs, productivity, households)}

\section{(1) Ascertainment of exposure}
(a) Secure record (e.g. surgical records, hospital records, and administrative records, national...)*
(b) Structured interview where blind to case/con- trol status*
(c) Interview not blinded to case/control status
(d) Written self-report or medical record only
(e) No description

(2) Same method of ascertainment for NCDs and comparators
(a) Yes*
(b) No
(c) No comparator group exist

(3) Non-response rate
(a) All participants included or same rate for both groups or respondents and non-respondents have the same characteristics*
(b) Non respondents described
(c) Rate different and no designation
(d) Response rate not described 


\section{References}

1. Alwan A, Armstrong T, Bettcher D, Branca F, Chisholm D, Ezzati M, Garfield R, MacLean D, Mathers C, Mendis S, Poznyak V, Riley L, Cho Tang K, Wild C. Global status report on noncommunicable diseases World Health Organization. 2010.

2. World Population Prospects: The 1998 Revision, vol. II, Sex and Age Distribution of the World Population. United Nations Population Division; 1999. http://www.un.org/esa/population/ pubsarchive/catalogue/catrpt1.htm\#1.

3. Wells G, Shea B, O'Connell D, Peterson J, Welch V, Losos M et al. The Newcastle-Ottawa score for non-randomized studies. 2010. http://www.ohri.ca/programs/clinical_epidemiology/oxford. asp. Accessed 13 Feb 2014.

4. Genova-Maleras R, Alvarez-Martin E, Morant-Ginestar C, Fernandez de Larrea-Baz N, Catala-Lopez F. Measuring the burden of disease and injury in Spain using disability-adjusted life years: an updated and policy-oriented overview. Public Health. 2012;126(12):1024-31.

5. Moran A, Zhao D, Gu D, Coxson P, Chen CS, Cheng J, et al. The future impact of population growth and aging on coronary heart disease in China: projections from the coronary heart disease policy model-China. BMC Public Health. 2008;8:394. doi:10.1186/1471-2458-8-394.

6. Etyang AO, Munge K, Bunyasi EW, Matata L, Ndila C, Kapesa $\mathrm{S}$, et al. Burden of disease in adults admitted to hospital in a rural region of coastal Kenya: an analysis of data from linked clinical and demographic surveillance systems. Lancet Global Health. 2014;2(4):E216-24. doi:10.1016/s2214-109x(14)70023-3.

7. Zhao Z, Winget M. Economic burden of illness of acute coronary syndromes: medical and productivity costs. BMC Health Serv Res. 2011;11:35. doi:10.1186/1472-6963-11-35.

8. Sasser AC, Rousculp MD, Birnbaum HG, Oster EF, Lufkin E, Mallet D. Economic burden of osteoporosis, breast cancer, and cardiovascular disease among postmenopausal women in an employed population. Women's Health Issues. 2005;15(3):97108. doi:10.1016/j.whi.2004.11.006.

9. Zheng H, Ehrlich F, Amin J. Productivity loss resulting from coronary heart disease in Australia. Appl Health Econ Health Policy. 2010;8(3):179-89. doi:10.2165/11530520-000000000-00000.

10. Anesetti-Rothermel A, Sambamoorthi U. Physical and mental illness burden: disability days among working adults. Popul Heath Manag. 2011;14(5):223-30. doi:10.1089/pop.2010.0049.

11. Short PF, Vasey JJ, BeLue R. Work disability associated with cancer survivorship and other chronic conditions. Psycho-Oncology. 2008;17(1):91-7. doi:10.1002/pon.1194.

12. Osler M, Martensson S, Prescott E, Carlsen K. Impact of gender, co-morbidity and social factors on labour market affiliation after first admission for acute coronary syndrome. A cohort study of Danish patients 2001-2009. PLoS ONE. 2014;. doi:10.1371/ journal.pone.0086758.

13. Catala-Lopez F, Fernandez de Larrea-Baz N, Morant-Ginestar C, Alvarez-Martin E, Diaz-Guzman J, Genova-Maleras R. The national burden of cerebrovascular diseases in Spain: a population-based study using disability-adjusted life years. Med Clin. 2014;. doi:10.1016/j.medcli.2013.11.040.

14. Katzenellenbogen JM, Vos T, Somerford P, Begg S, Semmens JB, Codde JP. Burden of stroke in indigenous Western Australians: a study using data linkage. Stroke. 2011;42(6):1515-21. doi:10.1161/strokeaha.110.601799.

15. Lopez-Bastida J, Oliva Moreno J, Worbes Cerezo M, Perestelo Perez L, Serrano-Aguilar P, Monton-Alvarez F. Social and economic costs and health-related quality of life in stroke survivors in the Canary Islands, Spain. BMC Health Serv Res. 2012;12:315.
16. Kang HY, Lim SJ, Suh HS, Liew D. Estimating the lifetime economic burden of stroke according to the age of onset in South Korea: a cost of illness study. BMC Public Health. 2011;11:646.

17. Kabadi GS, Walker R, Donaldson C, Shackley P. The cost of treating stroke in urban and rural Tanzania: a 6-month pilot study. Afr J Neurol Sci. 2013;32(2).

18. Gabriele W, Renate S. Work loss following stroke. Disabil Rehabil. 2009;31(18):1487-93. doi:10.1080/09638280802621432.

19. Hackett ML, Glozier N, Jan S, Lindley R. Returning to paid employment after stroke: the psychosocial outcomes in stroke (POISE) cohort study. PLoS ONE. 2012;. doi:10.1371/journal. pone.0041795.

20. Quinn AC, Bhargava D, Al-Tamimi YZ, Clark MJ, Ross SA, Tennant A. Self-perceived health status following aneurysmal subarachnoid haemorrhage: a cohort study. BMJ Open. 2014; doi:10.1136/bmjopen-2013-003932.

21. Traebert J, Schneider IJC, Colussi CF, de Lacerda JT. Burden of disease due to cancer in a Southern Brazilian state. Cancer Epidemiol. 2013;37(6):788-92. doi:10.1016/j.canep.2013.08.007.

22. Costilla R, Tobias M, Blakely T. The burden of cancer in New Zealand: a comparison of incidence and DALY metrics and its relevance for ethnic disparities. Aust N Z J Public Health. 2013;37(3):218-25.

23. Arrossi S, Matos E, Zengarini N, Roth B, Sankaranayananan R, Parkin M. The socio-economic impact of cervical cancer on patients and their families in Argentina, and its influence on radiotherapy compliance. Results from a cross-sectional study. Gynecol Oncol. 2007;105(2):335-40. doi:10.1016/j.ygyno.2006. 12.010 .

24. Taskila-Brandt T, Martikainen R, Virtanen SV, Pukkala E, Hietanen P, Lindbohm ML. The impact of education and occupation on the employment status of cancer survivors. Eur $\mathrm{J}$ Cancer. 2004;40(16):2488-93.

25. Torp S, Nielsen RA, Fossa SD, Gudbergsson SB, Dahl AA. Change in employment status of 5-year cancer survivors. Eur $\mathrm{J}$ Public Health. 2013;23(1):116-22. doi:10.1093/eurpub/ckr192.

26. Ekwueme DU, Guy GP Jr, Rim SH, White A, Hall IJ, Fairley TL, et al. Health and economic impact of breast cancer mortality in young women, 1970-2008. Am J Prev Med. 2014;46(1):71-9. doi:10.1016/j.amepre.2013.08.016.

27. Satariano WA, DeLorenze GN, Bush GW. The likelihood of returning to work after breast cancer. Public Health Rep. 1996;111(3):236-43.

28. Noeres D, Park-Simon TW, Grabow J, Sperlich S, Koch-Giesselmann H, Jaunzeme J, et al. Return to work after treatment for primary breast cancer over a 6-year period: results from a prospective study comparing patients with the general population. Support Care Cancer. 2013;21(7):1901-9. doi:10.1007/ s00520-013-1739-1.

29. Carlsen K, Ewertz M, Dalton SO, Badsberg JH, Osler M. Unemployment among breast cancer survivors. Scand J Public Health. 2014;42(3):319-28. doi:10.1177/1403494813520354.

30. Hauglann B, Benth JS, Fossa SD, Dahl AA. A cohort study of permanently reduced work ability in breast cancer patients. J Cancer Survivorship. 2012;6(3):345-56. doi:10.1007/s11764012-0215-0.

31. Ahn E, Cho J, Shin DW, Park BW, Ahn SH, Noh DY, et al. Impact of breast cancer diagnosis and treatment on work-related life and factors affecting them. Breast Cancer Res Treat. 2009;116(3):609-16. doi:10.1007/s10549-008-0209-9.

32. Maunsell E, Drolet M, Brisson J, Brisson C, Masse B, Deschenes L. Work situation after breast cancer: results from a population-based study. J Natl Cancer Inst. 2004;96(24): 1813-22. doi:10.1093/jnci/djh335. 
33. Bradley CJ, Dahman B. Time away from work: employed husbands of women treated for breast cancer. J Cancer Surviv. 2013;7(2):227-36. doi:10.1007/s11764-012-0263-5.

34. Balak F, Roelen CAM, Koopmans PC, Ten Berge EE, Groothoff JW. Return to work after early-stage breast cancer: a cohort study into the effects of treatment and cancer-related symptoms. J Occup Rehabil. 2008;18(3):267-72. doi:10.1007/s10926-0089146-z.

35. Lauzier S, Maunsell E, Drolet M, Coyle D, Hebert-Croteau N, Brisson J, et al. Wage losses in the year after breast cancer: extent and determinants among Canadian women. J Natl Cancer Inst. 2008;100(5):321-32. doi:10.1093/jnci/djn028.

36. Sjovall K, Attner B, Englund M, Lithman T, Noreen D, Gunnars $\mathrm{B}$, et al. Sickness absence among cancer patients in the prediagnostic and the post-diagnostic phases of five common forms of cancer. Support Care Cancer. 2012;20(4):741-7. doi:10.1007/ s00520-011-1142-8.

37. Bouknight RR, Bradley CJ, Luo Z. Correlates of return to work for breast cancer survivors. J Clin Oncol. 2006;24(3):345-53.

38. Fantoni SQ, Peugniez C, Duhamel A, Skrzypczak J, Frimat P, Leroyer A. Factors related to return to work by women with breast cancer in northern France. J Occup Rehabil. 2010; 20(1):49-58.

39. Mahmoudlou A, Yavari P, Abolhasani F, Khosravi A, Ramazani R. Estimation of the attributable burden of colorectal cancer in Iran in 2008. Iran J Epidemiol. 2014;9(4):1-9.

40. Bradley CJ, Lansdorp-Vogelaar I, Yabroff KR, Dahman B, Mariotto A, Feuer EJ, et al. Productivity savings from colorectal cancer prevention and control strategies. Am J Prev Med. 2011;41(2):e5-14. doi:10.1016/j.amepre.2011.04.008.

41. Yaldo A, Seal BS, Lage MJ. The cost of absenteeism and shortterm disability associated with colorectal cancer: a case-control study. J Occup Environ Med. 2014;56(8):848-51. doi:10.1097/ jom.0000000000000186.

42. Choi KS, Kim EJ, Lim JH, Kim SG, Lim MK, Park JG, et al. Job loss and reemployment after a cancer diagnosis in Koreans-a prospective cohort study. Psycho-Oncology. 2007;16(3):205-13. doi:10.1002/pon.1054.

43. Tevaarwerk AJ, Lee JW, Sesto ME, Buhr KA, Cleeland CS, Manola J, et al. Employment outcomes among survivors of common cancers: the Symptom Outcomes and Practice Patterns (SOAPP) study. J Cancer Surviv. 2013;7(2):191-202. doi:10. 1007/s11764-012-0258-2.

44. Bains M, Munir F, Yarker J, Bowley D, Thomas A, Armitage N, et al. The impact of colorectal cancer and self-efficacy beliefs on work ability and employment status: a longitudinal study. Eur J Cancer Care. 2012;21(5):634-41. doi:10.1111/j.1365-2354. 2012.01335.x.

45. Carlsen K, Harling H, Pedersen J, Christensen KB, Osler M. The transition between work, sickness absence and pension in a cohort of Danish colorectal cancer survivors. BMJ Open. 2013;. doi:10.1136/bmjopen-2012-002259.

46. Earle CC, Chretien Y, Morris C, Ayanian JZ, Keating NL, Polgreen LA, et al. Employment among survivors of lung cancer and colorectal cancer. J Clin Oncol. 2010;28(10):1700-5. doi:10.1200/jco.2009.24.7411.

47. Gordon L, Lynch BM, Newman B. Transitions in work participation after a diagnosis of colorectal cancer. Aust $\mathrm{N} \mathrm{Z} \mathrm{J}$ Public Health. 2008;32(6):569-74. doi:10.1111/j.1753-6405. 2008.00312.x.

48. Park JH, Park EC, Park JH, Kim SG, Lee SY. Job loss and reemployment of cancer patients in Korean employees: a nationwide retrospective cohort study. J Clin Oncol. 2008;26(8): 1302-9. doi:10.1200/jco.2007.14.2984.

49. Hauglann BK, SaltyteBenth J, Fossa SD, Tveit KM, Dahl AA. A controlled cohort study of sickness absence and disability pension in colorectal cancer survivors. Acta Oncol. 2014;53(6): 735-43. doi:10.3109/0284186x.2013.844354.

50. Roelen CA, Koopmans PC, Schellart AJ, van der Beek AJ. Resuming work after cancer: a prospective study of occupational register data. J Occup Rehabil. 2011;21(3):431-40.

51. Syse A, Tretli S, Kravdal O. Cancer's impact on employment and earnings-a population-based study from Norway. J Cancer Surviv. 2008;2(3):149-58.

52. Holden L, Scuffham PA, Hilton MF, Ware RS, Vecchio N, Whiteford HA. Which health conditions impact on productivity in working Australians? J Occup Environ Med. 2011;53(3): 253-7. doi:10.1097/JOM.0b013e31820d1007.

53. Dacosta Dibonaventura M, Paulose-Ram R, Su J, McDonald M, Zou KH, Wagner JS, et al. The impact of COPD on quality of life, productivity loss, and resource use among the elderly United States workforce. COPD J Chron Obstructive Pulmon Dis. 2012;9(1):46-57. doi:10.3109/15412555.2011.634863.

54. Alexopoulos EC, Burdorf A. Prognostic factors for respiratory sickness absence and return to work among blue collar workers and office personnel. Occup Environ Med. 2001;58(4):246-52. doi:10.1136/oem.58.4.246.

55. Kremer AM, Pal TM, Keimpema ARJ. Employment and disability for work in patients with COPD: a cross-sectional study among Dutch patients. Int Arch Occup Environ Health. 2006;80(1):78-86. doi:10.1007/s00420-006-0101-z.

56. Orbon KH, Schermer TR, van der Gulden JW, Chavannes NH, Akkermans RP, van Schayck OP, et al. Employment status and quality of life in patients with chronic obstructive pulmonary disease. Int Arch Occup Environ Health. 2005;78(6):467-74. doi:10.1007/s00420-005-0617-7.

57. Van Boven JFM, Vegter S, Van Der Molen T, Postma MJ. COPD in the working age population: the economic impact on both patients and government. COPD J Chron Obstruct Pulm Dis. 2013;10(6):629-39. doi:10.3109/15412555.2013.813446.

58. Nishimura S, Zaher C. Cost impact of COPD in Japan: opportunities and challenges? Respirology. 2004;9(4):466-73. doi:10. 1111/j.1440-1843.2004.00617.x.

59. Jansson SA, Andersson F, Borg S, Ericsson A, Jonsson E, Lundback B. Costs of COPD in Sweden according to disease severity. Chest. 2002;122(6):1994-2002. doi:10.1378/chest.122. 6.1994.

60. Nowak D, Dietrich ES, Oberender P, Uberla K, Reitberger U, Schlegel C, et al. Cost-of-illness Study for the Treatment of COPD in Germany. Krankheitskosten von COPD in Deutschland. Pneumologie. 2004;58(12):837-44. doi:10.1055/s-2004830143.

61. Lokke A, Hilberg O, Kjellberg J, Ibsen R, Jennum P. Economic and health consequences of COPD patients and their spouses in Denmark-1998-2010. COPD J Chron Obstruct Pulmon Dis. 2014;11(3):237-46. doi:10.3109/15412555.2013.839647.

62. Lokke A, Hilberg O, Tonnesen P, Ibsen R, Kjellberg J, Jennum $P$. Direct and indirect economic and health consequences of COPD in Denmark: a national register-based study: 1998-2010. BMJ Open. 2014;. doi:10.1136/bmjopen-2013-004069.

63. Darkow T, Kadlubek PJ, Shah H, Phillips AL, Marton JP. A retrospective analysis of disability and its related costs among employees with chronic obstructive pulmonary disease. J Occup Environ Med. 2007;49(1):22-30. doi:10.1097/JOM.0b013e3180 2db55f.

64. Klarenbach S, Stafinski T, Longobardi T, Jacobs P. The effect of renal insufficiency on workforce participation in the United States: an analysis using National Health and Nutrition Examination Survey III data. Am J Kidney Dis. 2002;40(6):11327. doi:10.1053/ajkd.2002.36854.

65. Helantera I, Haapio M, Koskinen P, Gronhagen-Riska C, Finne P. Employment of patients receiving maintenance dialysis and 
after kidney transplant: a cross-sectional study from Finland. Am J Kidney Dis. 2012;59(5):700-6. doi:10.1053/j.ajkd.2011. 08.025 .

66. Bradshaw D, Norman R, Pieterse D, Levitt NS. South African Comparative Risk Assessment Collaborating G. Estimating the burden of disease attributable to diabetes in South Africa in 2000. S Afr Med J. 2007;97(8 Pt 2):700-6.

67. Lavigne JE, Phelps CE, Mushlin A, Lednar WM. Reductions in individual work productivity associated with type 2 diabetes mellitus. Pharmacoeconomics. 2003;21(15):1123-34.

68. Dall TM, Mann SE, Zhang Y, Quick WW, Seifert RF, Martin J, et al. Distinguishing the economic costs associated with type 1 and type 2 diabetes. Popul Health Manag. 2009;12(2):103-10. doi:10.1089/pop.2009.12203.

69. Alavinia SM, Burdorf A. Unemployment and retirement and illhealth: a cross-sectional analysis across European countries. Int Arch Occup Environ Health. 2008;82(1):39-45. doi:10.1007/ s00420-008-0304-6.

70. Kessler RC, Greenberg PE, Mickelson KD, Meneades LM, Wang PS. The effects of chronic medical conditions on work loss and work cutback. J Occup Environ Med. 2001;43(3): 218-25. doi:10.1097/00043764-200103000-00009.

71. Adepoju OE, Bolin JN, Ohsfeldt RL, Phillips CD, Zhao H, Ory $\mathrm{MG}$, et al. Can chronic disease management programs for patients with type 2 diabetes reduce productivity-related indirect costs of the disease? Evidence from a randomized controlled trial. Popul Heath Manage. 2014;17(2):112-20. doi:10.1089/ pop.2013.0029.

72. Siegel R, Ward E, Brawley O, Jemal A. Cancer statistics, 2011: the impact of eliminating socioeconomic and racial disparities on premature cancer deaths. CA Cancer J Clin. 2011;61(4): 212-36.

73. DeSantis C, Siegel R, Bandi P, Jemal A. Breast cancer statistics, 2011. CA Cancer J Clin. 2011;61(6):409-18.

74. Mehnert A. Employment and work-related issues in cancer survivors. Crit Rev Oncol Hematol. 2011;77(2):109-30.

75. Molina R, Feliu J. The return to work of cancer survivors: the experience in Spain. Work. 2013;46(4):417-22. doi:10.3233/ Wor- 131677.

76. Steiner JF, Cavender TA, Main DS, Bradley CJ. Assessing the impact of cancer on work outcomes: what are the research needs? Cancer. 2004;101(8):1703-11.

77. Steiner JF, Nowels CT, Main DS. Returning to work after cancer: quantitative studies and prototypical narratives. Psychooncology. 2010;19(2):115-24.

78. van Muijen P, Weevers NL, Snels IA, Duijts SF, Bruinvels DJ, Schellart AJ, et al. Predictors of return to work and employment in cancer survivors: a systematic review. Eur J Cancer Care. 2013;22(2):144-60.

79. Kirsch F, Teuner CM, Menn P, Leidl R. Krankheitskosten fur Asthma und COPD bei Erwachsenen in der Bundesrepublik Deutschland. Gesundheitswesen. 2013;75(7):413-23.

80. Angeleri F, Angeleri VA, Foschi N, Giaquinto S, Nolfe G. The influence of depression, social activity, and family stress on functional outcome after stroke. Stroke. 1993;24(10):1478-83.

81. Bastida E, Pagan JA. The impact of diabetes on adult employment and earnings of Mexican Americans: findings from a community based study. Health Econ. 2002;11(5):403-13. doi:10.1002/hec.676.

82. Black-Schaffer RM, Osberg JS. Return to work after stroke: development of a predictive model. Arch Phys Med Rehabil. 1990;71(5):285-90.

83. Bogousslavsky J, Regli F. Ischemic stroke in adults younger than 30 years of age - cause and prognosis. Arch Neurol Chicago. 1987;44(5):479-82.
84. Boles M, Pelletier B, Lynch W. The relationship between health risks and work productivity. J Occup Environ Med. 2004;46(7):737-45. doi:10.1097/01.jom.0000131830.45744.97.

85. Bradley CJ, Bednarek HL. Employment patterns of long-term cancer survivors. Psychooncology. 2002;11(3):188-98.

86. Bradley CJ, Bednarek HL, Neumark D. Breast cancer survival, work, and earnings. J Health Econ. 2002;21(5):757-79.

87. Bradley CJ, Bednarek HL, Neumark D. Breast cancer and women's labor supply. Health Serv Res. 2002;37(5):1309-28.

88. Bradley CJ, Neumark D, Bednarek HL, Schenk M. Short-term effects of breast cancer on labor market attachment: results from a longitudinal study. J Health Econ. 2005;24(1):137-60.

89. Bradley CJ, Oberst K, Schenk M. Absenteeism from work: the experience of employed breast and prostate cancer patients in the months following diagnosis. Psychooncology. 2006;15(8):739-47.

90. Broekx S, Den Hond E, Torfs R, Remacle A, Mertens R, D'Hooghe T, et al. The costs of breast cancer prior to and following diagnosis. Eur J Health Econ. 2011;12(4):311-7. doi:10. 1007/s10198-010-0237-3.

91. Burton WN, Pransky G, Conti DJ, Chen CY, Edington DW. The association of medical conditions and presenteeism. J Occup Environ Med. 2004;46(6):S38-45. doi:10.1097/01.jom.000012 6687.49652 .44 .

92. Collins JJ, Baase CM, Sharda CE, Ozminkowski RJ, Nicholson $\mathrm{S}$, Billotti GM, et al. The assessment of chronic health conditions on work performance, absence, and total economic impact for employers. J Occup Environ Med. 2005;47(6):547-57. doi:10.1079/01.jom.0000166864.58664.29.

93. De Backer G, Leynen F, De Bacquer D, Clays E, Moreau M, Kornitzer M. Diabetes mellitus in middle-aged people is associated with increased sick leave: the BELSTRESS study. Int J Occup Environ Health. 2006;12(1):28-34.

94. Eaker S, Wigertz A, Lambert PC, Bergkvist L, Ahlgren J, Lambe M. Breast cancer, sickness absence, income and marital status. A study on life situation 1 year prior diagnosis compared to 3 and 5 years after diagnosis. PLoS ONE. 2011;. doi:10.1371/ journal.pone.0018040.

95. Fernandez De Larrea-Baz N, Alvarez-Martin E, Morant-Gines$\operatorname{tar}$ C, Genova-Maleras R, Gil A, Perez-Gomez B, et al. Burden of disease due to cancer in Spain. BMC Public Health. 2009;. doi:10.1186/1471-2458-9-42.

96. Ferro JM, Crespo M. Prognosis after transient ischemic attack and ischemic stroke in young adults. Stroke. 1994;25(8):1611-6.

97. Fu AZ, Qiu Y, Radican L, Wells BJ. Health care and productivity costs associated with diabetic patients with macrovascular comorbid conditions. Diabetes Care. 2009;32(12):2187-92. doi: $10.2337 / \mathrm{dc} 09-1128$.

98. Halpern MT, Stanford RH, Borker R. The burden of COPD in the U.S.A.: results from the Confronting COPD survey. Respir Med. 2003;97(Suppl C):S81-9.

99. Hansen JA, Feuerstein M, Calvio LC, Olsen CH. Breast cancer survivors at work. J Occup Environ Med. 2008;50(7):777-84. doi:10.1097/JOM.0b013e318165159e.

100. Herquelot E, Gueguen A, Bonenfant S, Dray-Spira R. Impact of diabetes on work cessation data from the GAZEL cohort study. Diabetes Care. 2011;34(6):1344-9. doi:10.2337/dc10-2225.

101. Hoyer M, Nordin K, Ahlgren J, Bergkvist L, Lambe M, Johansson $\mathrm{B}$, et al. Change in working time in a population-based cohort of patients with breast cancer. J Clin Oncol. 2012; 30(23):2853-60. doi:10.1200/jco.2011.41.4375.

102. Kappelle LJ, Adams HP Jr, Heffner ML, Torner JC, Gomez F, Biller J. Prognosis of young adults with ischemic stroke. A longterm follow-up study assessing recurrent vascular events and functional outcome in the Iowa Registry of Stroke in Young Adults. Stroke. 1994;25(7):1360-5. 
103. Kotila M, Waltimo O, Niemi ML, Laaksonen R, Lempinen M. The profile of recovery from stroke and factors influencing outcome. Stroke. 1984;15(6):1039-44.

104. Kruse M, Sorensen J, Davidsen M, Gyrd-Hansen D. Short and long-term labour market consequences of coronary heart disease: a register-based follow-up study. Eur J Cardiovasc Prev Rehabil. 2009;16(3):387-91. doi:10.1097/HJR.0b013e32832a3333.

105. Leigh JP, Romano PS, Schenker MB, Kreiss K. Costs of occupational COPD and asthma. Chest. 2002;121(1):264-72.

106. Leng CM. Description of a return-to-work occupational therapy programme for stroke rehabilitation in Singapore. Occup Ther Int. 2008;15(2):87-99. doi:10.1002/oti.248.

107. Lenneman J, Schwartz S, Giuseffi DL, Wang C. Productivity and health an application of three perspectives to measuring productivity. J Occup Environ Med. 2011;53(1):55-61. doi:10. 1097/JOM.0b013e3182029110.

108. Lindgren P, Glader EL, Jonsson B. Utility loss and indirect costs after stroke in Sweden. Eur J Cardiovasc Prev Rehabil. 2008;15(2):230-3. doi:10.1097/HJR.0b013e3282f37a22.

109. Mayfield JA, Deb P, Whitecotton L. Work disability and diabetes. Diabetes Care. 1999;22(7):1105-9. doi:10.2337/diacare. 22.7.1105.

110. McBurney CR, Eagle KA, Kline-Rogers EM, Cooper JV, Smith DE, Erickson SR. Work-related outcomes after a myocardial infarction. Pharmacotherapy. 2004;24(11):1515-23. doi:10. 1592/phco.24.16.1515.50946.

111. Molina R, Feliu J, Villalba A, San Jose B, Jimenez AM, Espinosa $\mathrm{E}$, et al. Employment in a cohort of cancer patients in Spain. A predictive model of working outcomes. Clin Transl Oncol. 2008;10(12):826-30.

112. Molina Villaverde R, Feliu Batlle J, Villalba Yllan A, Jimenez Gordo AM, Redondo Sanchez A, San Jose Valiente B, et al. Employment in a cohort of breast cancer patients. Occup Med (Lond). 2008;58(7):509-11. doi:10.1093/occmed/kqn092.

113. Nair K, Ghushchyan V, Van Den Bos J, Halford ML, Tan G, Frech-Tamas FH, et al. Burden of illness for an employed population with chronic obstructive pulmonary disease. Popul Heath Manag. 2012;15(5):267-75. doi:10.1089/pop.2011.0049.

114. Neau JP, Ingrand P, Mouille-Brachet C, Rosier MP, Couderq C, Alvarez A, et al. Functional recovery and social outcome after cerebral infarction in young adults. Cerebrovasc Dis. 1998; 8(5):296-302.

115. Niemi ML, Laaksonen R, Kotila M, Waltimo O. Quality of life 4 years after stroke. Stroke. 1988;19(9):1101-7.

116. O’Brien AN, Wolf TJ. Determining work outcomes in mild to moderate stroke survivors. Work. 2010;36(4):441-7.

117. Ohguri T, Narai R, Funahashi A, Nishiura C, Yamashita T, Yarita $\mathrm{K}$, et al. Limitations on work and attendance rates after employees with cancer returned to work at a single manufacturing company in Japan. J Occup Health. 2009;51(3):267-72.

118. Park JH, Park JH, Kim SG. Effect of cancer diagnosis on patient employment status: a nationwide longitudinal study in Korea. Psychooncology. 2009;18(7):691-9.

119. Peters GO, Buni SG, Oyeyemi AY, Hamzat TK. Determinants of return to work among Nigerian stroke survivors. Disabil Rehabil. 2013;35(6):455-9. doi:10.3109/09638288.2012.697251.

120. Peuckmann V, Ekholm O, Sjogren P, Rasmussen NK, Christiansen $\mathrm{P}$, Moller $\mathrm{S}$, et al. Health care utilisation and characteristics of long-term breast cancer survivors: nationwide survey in Denmark. Eur J Cancer. 2009;45(4):625-33.

121. Robinson N, Yateman NA, Protopapa LE, Bush L. Unemployment and diabetes. Diabet Med. 1989;6(9):797-803.

122. Roelen CAM, Koopmans PC, de Graaf JH, Balak F, Groothoff JW. Sickness absence and return to work rates in women with breast cancer. Int Arch Occup Environ Health. 2009;82(4):5436. doi:10.1007/s00420-008-0359-4.

123. Saeki S, Toyonaga T. Determinants of early return to work after first stroke in Japan. J Rehabil Med. 2010;42(3):254-8.

124. Short PF, Vasey JJ, Tunceli K. Employment pathways in a large cohort of adult cancer survivors. Cancer. 2005;103(6): 1292-301.

125. Sin DD, Stafinski T, Ng YC, Bell NR, Jacobs P. The impact of chronic obstructive pulmonary disease on work loss in the United States. Am J Respir Crit Care Med. 2002;165(5):704-7.

126. Spelten ER, Verbeek JH, Uitterhoeve AL, Ansink AC, van der Lelie J, de Reijke TM, et al. Cancer, fatigue and the return of patients to work-a prospective cohort study. Eur J Cancer. 2003;39(11):1562-7.

127. Stewart DE, Cheung AM, Duff S, Wong F, McQuestion M, Cheng $\mathrm{T}$, et al. Long-term breast cancer survivors: confidentiality, disclosure, effects on work and insurance. Psychooncology. 2001;10(3):259-63.

128. Strassels SA, Smith DH, Sullivan SD, Mahajan PS. The costs of treating COPD in the United States. Chest. 2001;119(2):344-52.

129. Taskila T, Martikainen R, Hietanen P, Lindbohm ML. Comparative study of work ability between cancer survivors and their referents. Eur J Cancer. 2007;43(5):914-20.

130. Teasell RW, McRae MP, Finestone HM. Social issues in the rehabilitation of younger stroke patients. Arch Phys Med Rehabil. 2000;81(2):205-9.

131. Timperi AW, Ergas IJ, Rehkopf DH, Roh JM, Kwan ML, Kushi LH. Employment status and quality of life in recently diagnosed breast cancer survivors. Psycho-Oncology. 2013;22(6):1411-20. doi:10.1002/pon.3157.

132. Vanderwouden JC, Greavesotte JGW, Greaves J, Kruyt PM, Vanleeuwen O, Vanderdoes E. Occupational reintegration of long-term cancer survivors. J Occup Environ Med. 1992;34(11): 1084-9.

133. Vestling M, Tufvesson B, Iwarsson S. Indicators for return to work after stroke and the importance of work for subjective well-being and life satisfaction. J Rehabil Med. 2003;35(3): 127-31.

134. Wang PS, Beck A, Berglund P, Leutzinger JA, Pronk N, Richling D, et al. Chronic medical conditions and work performance in the health and work performance questionnaire calibration surveys. J Occup Environ Med. 2003;45(12):1303-11.

135. Ward MM, Javitz HS, Smith WM, Whan MA. Lost income and work limitations in persons with chronic respiratory disorders. J Clin Epidemiol. 2002;55(3):260-8.

136. Wozniak MA, Kittner SJ, Price TR, Hebel JR, Sloan MA, Gardner JF. Stroke location is not associated with return to work after first ischemic stroke. Stroke. 1999;30(12):2568-73.

137. Yabroff KR, Lawrence WF, Clauser S, Davis WW, Brown ML. Burden of illness in cancer survivors: findings from a population-based national sample. J Natl Cancer Inst. 2004;96(17): 1322-30. 